\title{
Tropical Warm Pool International Cloud Experiment (TWP-ICE): Cloud and Rain Characteristics in the Australian Monsoon
}

May 2004

P. T. May and C. Jakob

Bureau of Meteorology Research Centre

Victoria 3001, Australia

J. H. Mather

Pacific Northwest National Laboratory

Richland, Washington

Work supported by the U.S. Department of Energy, Office of Science, Office of Biological and Environmental Research 



\section{SUMMARY}

The impact of oceanic convection on its environment and the relationship between the characteristics of the convection and the resulting cirrus characteristics is still not understood. An intense airborne measurement campaign combined with an extensive network of ground-based observations is being planned for the region near Darwin, Northern Australia, during January-February, 2006, to address these questions. The Tropical Warm Pool - International Cloud Experiment (TWP-ICE) will be the first field program in the tropics that attempts to describe the evolution of tropical convection, including the large scale heat, moisture, and momentum budgets, while at the same time obtaining detailed observations of cloud properties and the impact of the clouds on the environment. The emphasis will be on cirrus for the cloud properties component of the experiment. Cirrus clouds are ubiquitous in the tropics and have a large impact on their environment but the properties of these clouds are poorly understood. A crucial product from this experiment will be a dataset suitable to provide the forcing and testing required by cloud-resolving models and parameterizations in global climate models. This dataset will provide the necessary link between cloud properties and the models that are attempting to simulate them.

The experiment is a collaboration between the U.S. Department of Energy (DOE) Atmospheric Radiation Measurement (ARM) Program, the Bureau of Meteorology (BoM), the National Aeronautics and Space Administration (NASA), the European Commission DG RTD-1.2, and several United States, Australian, Canadian, and European Universities. This experiment will be undertaken over a 4-week period in early 2006. January and February corresponds to the wet phase of the Australia monsoon. This season has been selected because, despite Darwin's coastal location, the convection that occurs over and near Darwin at this time is largely of maritime origin with a large fetch over water. Based on previous experiments, the convection appears typical of maritime convection with widespread convection that has complex organization, but is not as deep or as intense as continental or coastal convection. Therefore, it is expected that the convection and cloud characteristics will be representative of conditions typical for wide areas of the tropics.

TWP-ICE seeks to build on a number of past experiments. Tropical Ocean Global Atmosphere-Coupled Ocean Atmosphere Response Experiment (TOGA-COARE) was an extensive tropical campaign that focused largely on the organization of deep convection and on processes associated with the ocean/atmosphere interface. More recently, the Cirrus Regional Study of Tropical Anvils and Cirrus Layers-Florida Area Cirrus Experiment (CRYSTAL-FACE) and Egrett Microphysics Experiment with Radiation Lidar and Dynamics (EMERALD) experiment have focused on deep organized convection systems typical of coastal areas. In both of these experiments, the emphasis was on observing properties of cirrus clouds and processes of the upper troposphere. There was some effort during CRYSTAL-FACE to describe the convective environment through the use of the Eldora radar, ground-based weather radars, and radiosondes; however, the emphasis of the experiment was on upper troposphere characterization rather than convective processes.

The Darwin experiment is being designed to include the characterization of cirrus and the upper troposphere along with the convective environment. This dual focus is extremely important. A primary reason for ARM's attention to tropical cirrus is to improve the representation of these clouds in climate models. While characterization of tropical cirrus will be valuable on its own, as few such observations are currently available, this information without corresponding information about the processes that led to 
the cirrus formation will be of limited use to cloud modelers. The dual focus of TWP-ICE will result in a dataset that can be used to address a range of important scientific questions related to tropical clouds. Specific goals of the experiment are as follows:

1. Make detailed measurements of the cirrus microphysics and how they relate to storm intensity and proximity (spatial and temporal) to the parent convection.

2. Verify remotely sensed microphysical measurements.

3. Provide datasets for forcing cloud-resolving and single-column models that will attempt to simulate the observed characteristics and impacts.

4. Document the evolution of oceanic convective clouds from the early convection phase through to the remnant cirrus with particular emphasis on their microphysics.

5. Measure the dynamical and radiative impacts of the cloud systems.

6. Characterize the environment in which the cloud systems occur.

7. Document the evolution of the convective boundary layer throughout the diurnal cycle and through the lifecycle of convective systems.

The European participants will also focus on issues such as troposphere/stratosphere exchange, and the water budget of the lower stratosphere while there will be a large chemistry component from NASA focusing on short-lived species generated in the convection. Other groups will also be adding smaller components focused on specific areas of research, such as convectively generated gravity waves, that can use the data gathered by ARM synergistically, but are not core areas of the program.

Observations of cloud properties will be provided by an extensive set of in situ and remote sensing instruments. The Darwin ARM site will provide continuous measurements of cloud properties through remote sensing retrievals. A second set of instruments will be deployed on a ship in the Timor Sea, approximately $100 \mathrm{~km}$ northwest of Darwin. Added to these surface-based observations will be several research aircraft including the NASA WB-57, DOE Proteus, DLR Falcon, and Geophysica, as well as three aircraft provided by Airborne Research Australia (ARA): the Egrett, King Air, Dimona. These aircraft fulfill a variety of observational requirements to address the science goals.

To fully describe cirrus cloud properties, both in situ and remote sensing airborne observations are required. The WB-57 is primarily an in situ platform while the Proteus is capable of making both in situ and remote sensing measurements. The Geophysica is again a primarily in situ platform, but includes accurate water vapor measurements and has by far the highest operating ceiling $(>20 \mathrm{~km})$ of the aircraft in the campaign. With a ceiling of approximately $15 \mathrm{~km}$, the Proteus will be able to fly above much of the cirrus thereby providing a useful top-down view of the cloud systems. The King Air will complement the Proteus by adding remote sensing from the middle troposphere with both lidar and 94-GHz cloud radar while the Falcon carries a lidar and sensors for in situ measurements of cloud microphysics. In some cases, cloud attenuation will preclude the Proteus instruments from observing cloud properties through the column, a bottom-up view from the King Air will help fill this gap. The Egrett is primarily an in situ aircraft with a somewhat lower ceiling than the WB-57 or Proteus. The addition of the Egrett adds considerable flexibility for spatial sampling. Finally, the Dimona is a small boundary layer aircraft. The 
purpose of this aircraft is to characterize surface turbulent and radiative fluxes throughout the experiment region. This aircraft is one part of the set of observations needed to describe the convection environment.

The observation strategy for describing the convective environment includes several elements: a network of radiosonde stations, a pair of precipitation radars, wind profilers, surface flux stations, and the boundary layer aircraft. A ring of five radiosonde stations will encircle the station at Darwin. The Darwin sonde station is collocated with the BoM facility and the ARM site. Sondes will be launched with high temporal resolution (3-hourly launches) from all six sites to provide a detailed description of the experiment region's lateral boundary and core. This will be an unprecedented dataset for a tropical location. The radius of this sonde network will be 100 to $150 \mathrm{~km}$. This dimension was selected to match the range of the dual Doppler radars stationed near Darwin. These radars will provide a three-dimensional (3D) view of convection intensity throughout the Darwin region. Turbulent and radiative fluxes at the lower boundary will be characterized with (1) instruments at selected sites, including a ship; and (2) observations from the boundary layer aircraft. The instrumented sites will be positioned to characterize diverse surface types while the aircraft will provide the means to apply these point measurements to the larger region.

Darwin is a coastal site and it will be important to characterize the oceanic region off the Australia coast. For this purpose, the Commonwealth Scientific and Industrial Research Organization (CSIRO) research vessel Southern Surveyor will be stationed in the Timor Sea to the northwest of Darwin. This ship will serve as a launch site for sondes, to complete the ring around Darwin and will also carry surface flux instruments. Remote sensing instruments are also being considered for the ship. The addition of these instruments will provide a complete second surface site. This capability will increase the likelihood of obtaining good coordinated surface/aircraft observations.

Finally, satellites will be important for characterizing the upper boundary of the experiment region. Geostationary observations will provide top of atmosphere (TOA) fluxes over the entire domain while more specialized satellite products will be collected both as an additional source of information for understanding cloud processes and to test satellite remote sensing retrievals in much the same way that surface-based retrievals will be tested. Of particular interest will be comparisons of in situ aircraft observations of cirrus properties with retrievals from the Cloud Satellite (CloudSat) and Cloud-Aerosol Lidar and Infrared Pathfinder Satellite Observations (CALIPSO) satellites, which are both due to be launched in early 2005.

The occurrence of tropical clouds in the form of shallow non-precipitating cumulus to deep precipitating cumulonimbus with extensive anvils has a significant and fundamental impact on the atmospheric energy balance. Understanding the properties of these clouds and parameterizing their impact within climate prediction models is one of the major challenges facing the international community. It is well recognized that the representation of these process is a major uncertainty in our ability to represent and predict climate. In that context modeling activities, including the application of cloud resolving and single-column models as well as a suite of numerical weather prediction (NWP) models, will form a major component of the experiment activities. Those activities include pre-experiment model evaluation, NWP support during experiment and a large post-experiment program that will make use of the collected data in evaluating and improving the representation of cloud, convective and radiative processes in the models. 
The ARM Program has been taking long-term observations to provide data to address the cloud characteristics and their radiative effects. TWP-ICE will provide important in situ data to both verify the remote retrievals and to provide high resolution in situ data that cannot be remotely sensed. The experiment will also provide an invaluable description of the convective environment. Together, the observations of cloud properties and the atmospheric state will make this a dataset unique for improving cloud parameterizations in the tropics. 


\section{CONTENTS}

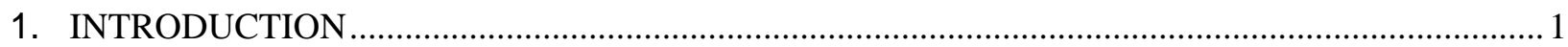

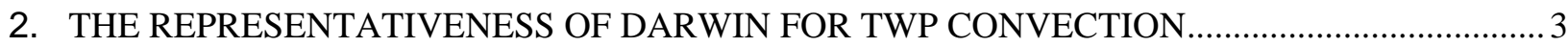

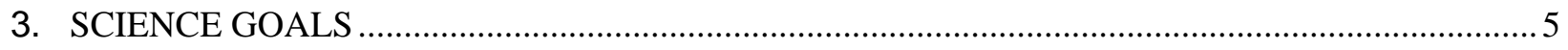

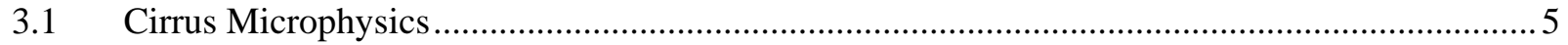

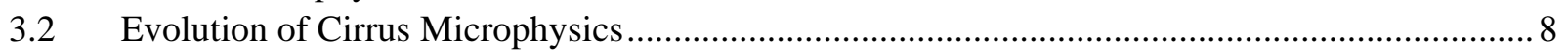

3.3 Effect of Convective Strength on Anvil Properties........................................................... 8

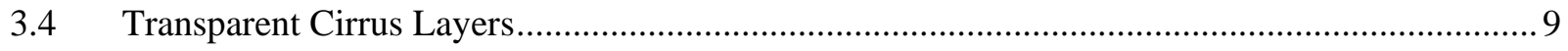

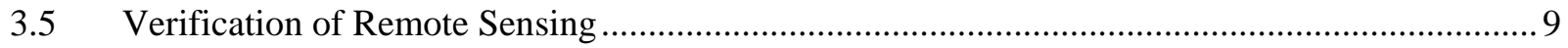

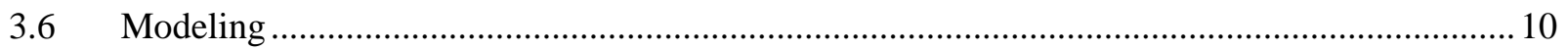

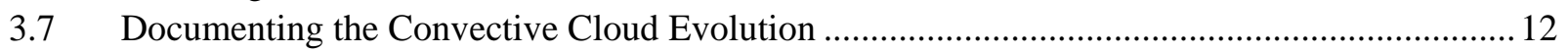

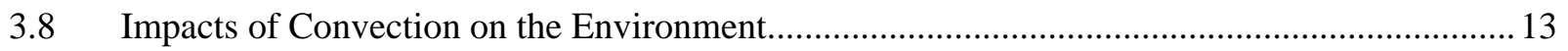

3.9 Relationship Between Convection and the Large-Scale Flow ................................................15

3.10 Relationship Between the Boundary Layer and Deep Convection ..........................................16

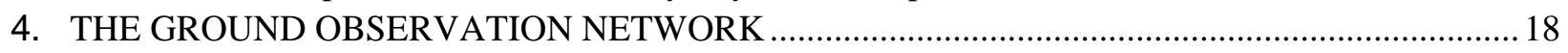

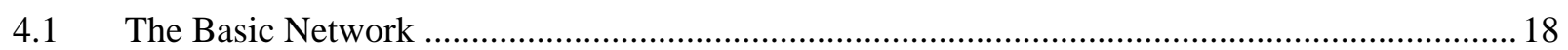

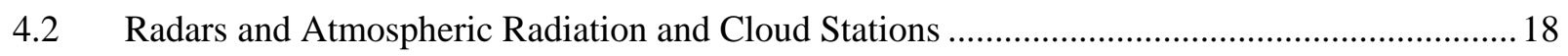

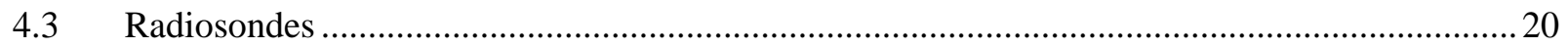

4.4 The CSIRO Research Vessel, Southern Surveyor ............................................................ 20

4.5 The Pacific Northwest National Laboratory Atmospheric Remote Sensing Laboratory ............. 21

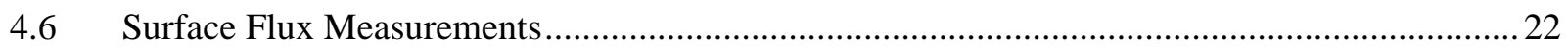

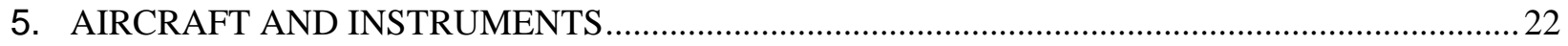

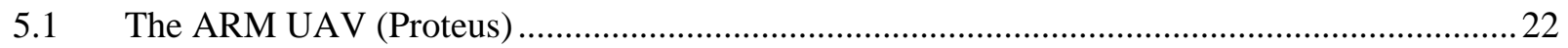

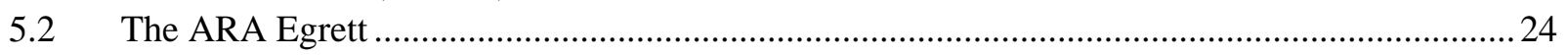

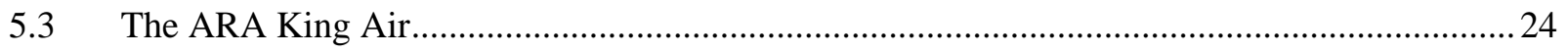

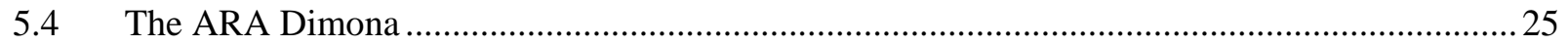

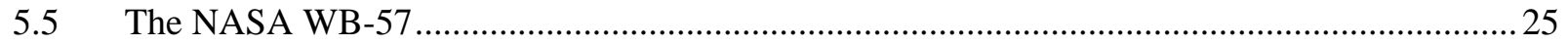

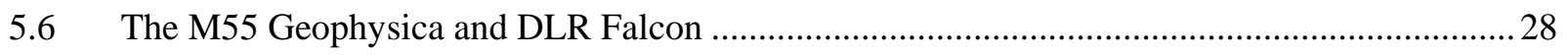

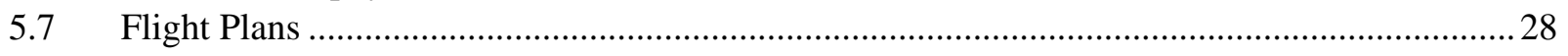

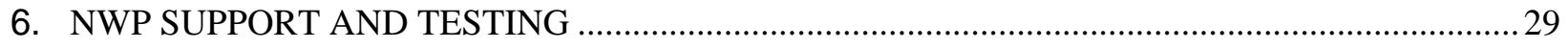

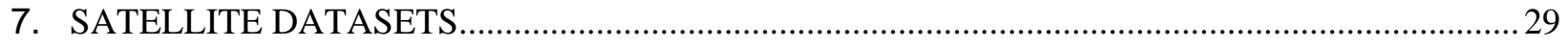

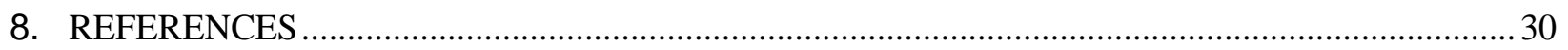

Appendix A - Proteus Instruments ............................................................................................... A.1

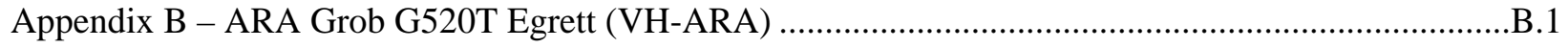

Appendix C - Contacts ............................................................................................................ 1 


\section{FIGURES}

1 Cloud regimes identified from ISCCP histograms................................................................... 4

2 Relative frequencies of occurrence of the ISCCP cloud regimes. ................................................. 6

3 A cross section of the lidar backscatter returns and the in situ data from the cloud particle imager .... 7

4 Plan view of the reflectivity during monsoonal convection (0700 UTC December 12, 2001).......... 14

5 Constant altitude cross section through a segment of a squall line crossing Darwin

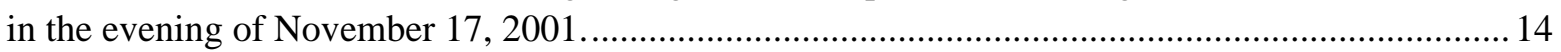

$6 \quad$ Location of main operations and the additional measurement sites................................................ 17

$7 \quad$ Example of a Dual Doppler retrieval of circulation within a storm cell ........................................... 19

8 Time-height cross section of C-Pol reflectivity and polarimetric classification of hydrometeors...... 20

\section{TABLES}

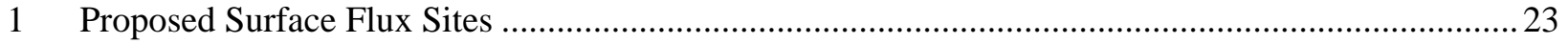

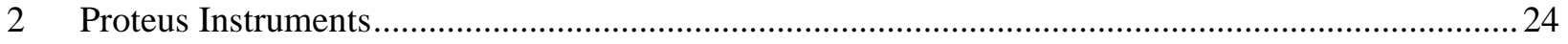

3 A list of instruments to be carried by the Egrett. ............................................................................. 25

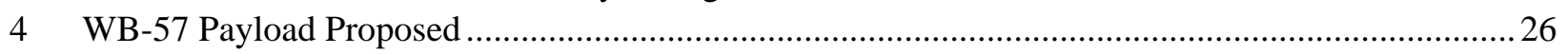

5 Instrument list for the M55 Geophysica and DLR Falcon Aircraft .................................................27 


\title{
TROPICAL WARM POOL - INTERNATIONAL CLOUD EXPERIMENT (TWP-ICE)
}

\author{
SCIENCE PLAN
}

\section{INTRODUCTION}

Deep convection over oceans has a major effect on the earth's climate. This is through the redistribution of heat and moisture vertically and horizontally within the convection and through the radiative impacts of the large "anvil" cirrus shield that mesoscale complexes of convection develop. Tropical cirrus are high cold clouds composed of ice crystals. They are often formed by the outflow from deep convective clouds. The cirrus anvils may have a spatial extent two orders of magnitude greater than the parent convection and persist for hours, even after the convective activity has decayed completely. Generally, these clouds play an important role in the radiation balance of the atmosphere and dominate the cloud radiative forcing in the tropics (Ramanathan et al. 1989; Rossow and Schiffer 1991). The ice crystals scatter incoming radiation acting to cool the earth's surface, but the clouds are also efficient absorbers of the upwelling infrared radiation from the ground. The precise balance depends on the detailed microphysical structure of the cirrus.

Tropical cirrus has been an area of active research over a long period. Describing the characteristics of cirrus is one of the key goals of the Atmospheric Radiation Measurement (ARM) Program. Suites of remote sensing devices are used to estimate the microphysical structure of cirrus. There have also been several aircraft experiments that have included observations of tropical cirrus, but there are relatively few high quality in situ datasets obtained near the suites of ground based instrumentation. For example, there have recently been two field experiments that seek to address this in part. The first is the large Cirrus Regional Study of Tropical Anvils and Cirrus Layers-Florida Area Cirrus Experiment (CRYSTALFACE) in Florida (http://cloud1.arc.nasa.gov/crystalface/science.html) and a more modest experiment around Darwin, Northern Australia, in November 2002. These experiments sampled clouds associated with deep coastal and continental convection, although the CRYSTAL-FACE experiment also planned on sampling oceanic convection.

There also have been many field programs focused on the structure and evolution of deep tropical convection. Particularly notable projects include the Tropical Ocean Global Atmosphere-Coupled Ocean Atmosphere Response Experiment (TOGA-COARE) over the tropical Pacific, the Australian Monsoon Experiment/Equatorial Mesoscale Experiment (AMEX/EMEX) and the Maritime Continent Thunderstorm Experiment (MCTEX) in the Australia region. These projects studied the initiation, evolution, and organization of convection including profiles of the net heating and drying associated with the convection, but these projects have not made the link to radiatively important clouds.

Some significant morphological differences exist between deep convection in oceanic systems compared to continental and coastal systems (e.g., Keenan and Carbone 1992). The continental and coastal convection tends to be deeper and better organized with larger amplitude vertical motions. This is also manifested in being more electrically active and by a reflectivity structure that shows high values extending well above the freezing level. Oceanic systems, on the other hand, tend to be more wide 
spread, but have reflectivity decreasing rapidly above the freezing level. The horizontal structure of the oceanic monsoon storm systems is often much more complex than that of systems encountered during the build up period. These oceanic systems are widespread across the maritime continent and warm pool region of the tropical Pacific. The oceanic clouds still reach to the tropopause.

The different vertical structure of convection relates to the vertical velocity structure within the storm and must affect the mass flux into the storm anvils and resulting cirrus. The radar network at Darwin is ideally suited to characterize the convective development and evolution of the clouds. The weather radars have some ability to observe non-precipitating cloud and are located such that they can be used for dual Doppler syntheses of the three-dimensional (3D) wind field within the cloud systems circulation within the clouds. Another difference between continental and oceanic convection is that the aerosol characteristics of the boundary layer air are quite different. This is likely to impact the resulting microphysical characteristics of the cirrus. The aim of this experiment is to make cirrus measurements within oceanic storms near Darwin.

Darwin is a coastal location in northern Australia. It is the site of the third ARM Atmospheric Radiation and Cloud Stations (ARCS) (http://www.arm.gov) and is well sited to sample both continental/coastal and oceanic convection. Darwin is affected by a strong monsoonal circulation. The monsoon season typically begins in middle to late December and usually persists through mid-February. During this time, monsoonal periods will last for about 3 to 4 weeks at a time with an approximate one-week "break" between them. Thus, a Darwin-based network is ideally sited to study cirrus characteristics from both continental and oceanic regimes.

The structure and characteristics of deep convection in the region have been described in a number of review articles (McBride [1987], Manton and McBride [1992], McBride [1995], AMS Monograph chapter), as well as overview papers from the tropical experiments that operated out of Darwin: Gunn et al. (1989) for AMEX; Webster and Houze (1991) for EMEX; Russell et al. (1993) for Tropical Stratosphere-Troposphere Exchange Project (STEP); and Keenan et al. (2000) for MCTEX. As described in these references, the major global monsoon heat source is located over Northern Australia during January. Keenan et al. (1989) documented diurnal variation of convection during AMEX-EMEX, and showed that for monsoon conditions the diurnal cycle is relatively weak with a nocturnal maximum, consistent with much of the tropical oceans, while during break periods the diurnal cycle is strong with a late afternoon maximum in convective activity. Several papers, such as Mapes and Houze 1992 (QJ article), and Keenan and Carbone (1992), documented the mesoscale structure of convective complexes in the region. But significant questions remain on the factors controlling the organization of the convection, the diurnal cycle, and the impact of the convection on the near environment. The thermodynamic structure and ice crystal properties near the tropopause level were documented by Selkirk (1993) and Kelley et al. (1993), respectively.

The underlying aim of this experiment is to provide a dataset that provides as complete a picture as possible of the evolution of (monsoonal) deep oceanic convection. This includes detailed observations of the synoptic and mesoscale environment through to the cloud scale structure and cloud microphysics. Darwin's extensive local infrastructure makes it unique, and this combination of measurements of oceanic deep convective systems probably cannot be undertaken anywhere else in the world. The combination of the ground-based network and aircraft-based observations will be a powerful tool for studying cloud characteristics in a complex environment. 


\section{THE REPRESENTATIVENESS OF DARWIN FOR TWP CONVECTION}

Because the experiment is aimed primarily at cloud systems representative of the tropical warm pool, a legitimate question is how representative the Darwin area, with its associated land mass and coastal regions, is of the warm pool region? Recent studies by Petersen and Rutledge (2001) showed that convection over Darwin during the monsoon was similar to that over the western Pacific, but had a tendency to be more electrically active. They ascribed this result to some coastal and "break period" convection, which is known to be very electrically active, thus contaminating their sample. Likewise, studies of the most intense tropical convection by Toracinta et al. (2002) showed that Darwin was similar to convection across the warm pool region. Long-term satellite datasets can be used to address this question with respect to cloud characteristics.

Jakob and Tselioudis (2003) have recently analyzed the major cloud regimes that are present in the Tropical Western Pacific (TWP) as seen in data from the International Satellite Cloud Climatology Program (ISCCP). The basic regimes identified in their study will be used here to assess the representativeness of the cloud regimes encountered in the Darwin area during the wet season. The study is based on a cluster analysis on histograms of cloud optical thickness $(\tau)$ and cloud top pressure (CTP) for the years 1999-2000. Each histogram represents the $\tau$-CTP distribution in a $280 \mathrm{x} 280 \mathrm{~km}^{2}$ area at a given time. The area for the TWP analysis is $10^{\circ} \mathrm{N}$ to $10^{\circ} \mathrm{S}$ and $130^{\circ} \mathrm{E}$ to $170^{\circ} \mathrm{E}$. For the Darwin area, four ISCCP gridpoints surrounding Darwin are analyzed. Together they span the area of roughly $10^{\circ} \mathrm{S}$ to $15^{\circ} \mathrm{S}$ and $127^{\circ} \mathrm{E}$ to $133^{\circ} \mathrm{E}$.

Figure 1 shows the basic results of the analysis. The four left panels show the regime-average histograms, which identify the four major cloud regimes encountered in the TWP. They encompass (from top to bottom) a suppressed regime dominated by shallow clouds (SSC), a suppressed regime dominated by transparent cirrus (STC), a deep convective regime dominated by cirrus (CC), and a deep convective regime dominated by widespread occurrence of optically thick clouds (CD). These regimes occur in $46 \%, 17 \%, 23 \%$, and $14 \%$ of the cases, respectively. The four middle panels show the results of an identical cluster analysis, this time carried out for the four points surrounding Darwin for the years 19992000. It is evident that apart from the SSC regime the regime averages identified over Darwin are virtually identical to those in the TWP. The difference in the SSC regime is marked by a strong reduction in total cloud cover ( 0.25 instead of 0.41 in the TWP). This can be explained by the inclusion of the dry season in the cluster analysis, contributing many virtually cloud-free situations to the SSC regime. This is more evident in the four right panels in Figure 1, which show the regime-averaged histograms for the wet season (defined as November through March, NDJFM) only. Those were calculated by classifying each histogram based on its distance to the regime averages identified in the cluster analysis for Darwin, which are shown in the middle panels. It is evident that during the wet season, all four cloud regimes are similar to those in the TWP. Their frequencies of occurrence in that season are 33\%, 24\%, 27\%, and 17\%, respectively.

While the ISCCP histograms provide a rather specific and somewhat limited view of the cloud fields, this view is based on the top of atmosphere (TOA) radiative cloud characteristics. Understanding the relation of the latter to cloud and convective properties is a major aim of the experiment, giving significance to the above results. 

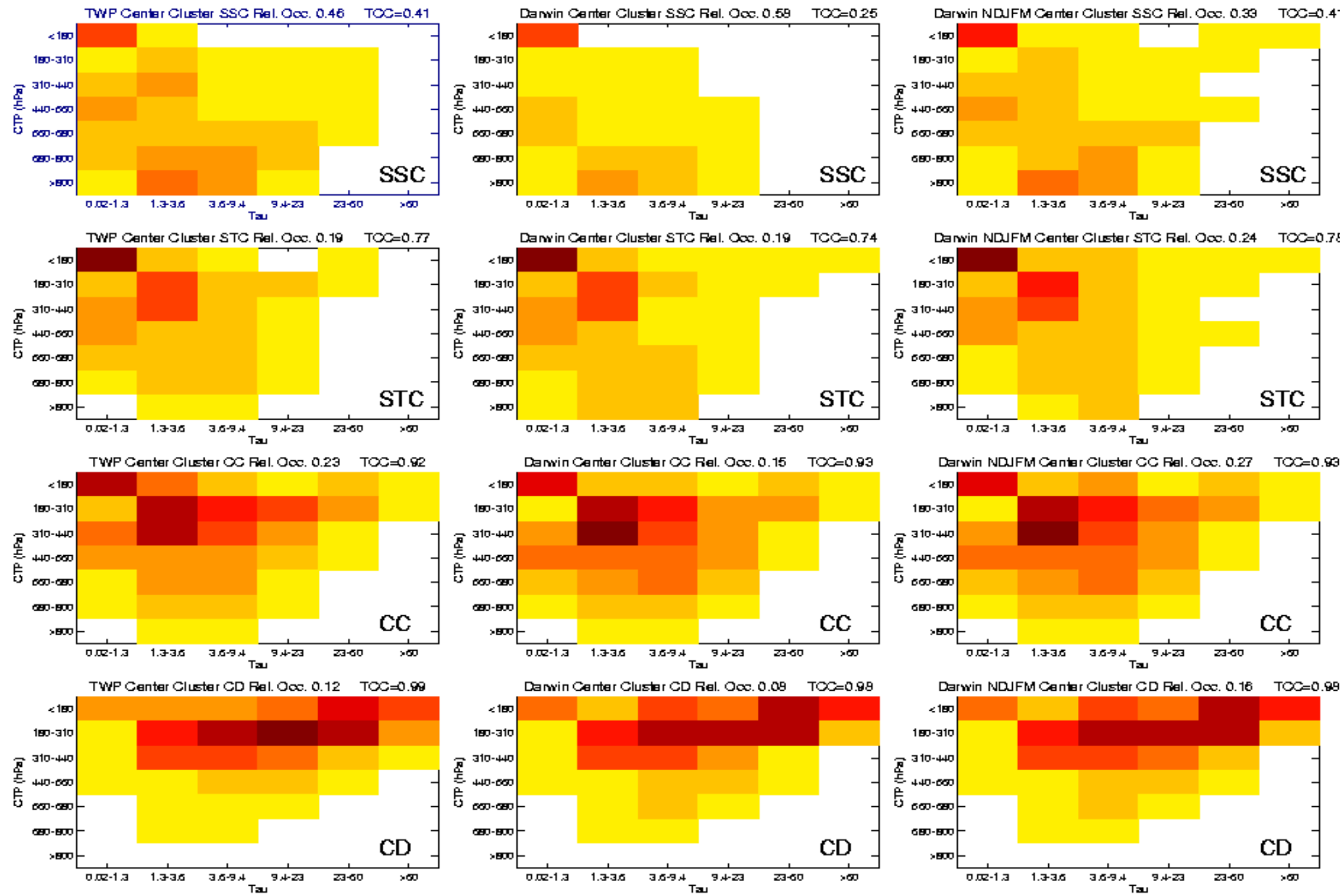

Figure 1. Cloud regimes identified from ISCCP histograms. Left: TWP 1999-2000; Middle: Darwin 1999-2000; Right: Darwin NDJFM 1999-2000. See text for details. 
Because the experiment will take place during monsoon conditions, the analysis has been extended by calculating the frequency of occurrence of the cloud regimes for westerly (monsoon) and easterly (buildup, break, or decay) wind regimes. Wind direction at $700 \mathrm{hPa}$ has been used to identify the wind regime, with easterly directions between $0^{\circ}$ and $180^{\circ}$ and westerly directions between $180^{\circ}$ and $360^{\circ}$. The results are summarized in Figure 2. The top panels show the frequency of occurrence of the for regimes for the TWP during the years 1999-2000 (left) and Darwin in NDJFM 1999-2000 (right), while the bottom panels separate the data into easterly (left) and westerly (right) regimes. The main difference between a westerly and easterly wind regime is a reduction in the occurrence of suppressed conditions and an increase in deep convective activity. In particular the CD regime, representing the presence of widespread optically thick clouds, is largely enhanced in westerly conditions pointing to the widespread presence of deep convective cloud systems as typical for monsoon conditions. Note however, that even under monsoon influence, suppressed conditions can occur, at least in part of the area under investigation. During easterly periods, the suppressed regimes dominate the cloud conditions with a fair number of cases ( $>25 \%)$ of the STC regime, another objective of the experiment.

It can be concluded that the area around Darwin contains all the cloud regimes encountered in the TWP with deep convection present in almost $60 \%$ of the cases under monsoon conditions as well as about $20 \%$ relative occurrence of a regime dominated by transparent cirrus. Hence, the cloud types that form the experiment objectives are virtually guaranteed to be encountered during the experiment.

\section{SCIENCE GOALS}

This experiment seeks to provide a complete dataset describing the environment of oceanic convection, structure, and evolution of this convection and the resulting cloud fields and radiative impacts. This whole system description has not been attempted before. A key goal will be to provide datasets that allow the derivation of forcing and evaluation datasets for modeling studies. The datasets will provide detailed observations of the structure and evolution of the cloud systems on the scale of a global climate model grid box. This will include the evolution and structure of the parent convection and the subsequent cirrus cloud structure and its evolution after the convection has decayed. These two factors have not been addressed simultaneously to this level of detail in any previous field program. This is particularly the case as a detailed sounding network and flux measurements will provide a dataset for forcing cloud resolving and single-column models (SCMs) for comparison with the observational dataset. Once these models have been validated against observations, they will be used to provide data on processes that cannot be directly measured. Specific areas of study that will be undertaken are discussed in the following section.

\subsection{Cirrus Microphysics}

One of the main goals of the experiment is to document the microphysical characteristics of cirrus in the tropics. ARM has acquired several years of tropical cirrus data from Darwin, Manus, and Nauru with observations from the millimeter wave cloud radar (MMCR) and micropulse lidar (MPL) as well as passive instruments such as the infrared thermometer (IRT) and atmospheric emitted radiance interferometer (AERI). Documenting the vertical distribution of particle habits with in situ observations will significantly constrain the retrievals of cloud properties from the vertically pointing ground-based instruments. Few observations of tropical cirrus microphysics have been obtained, and none of those included the complete suite of tools now available for parameters such as total water content and 

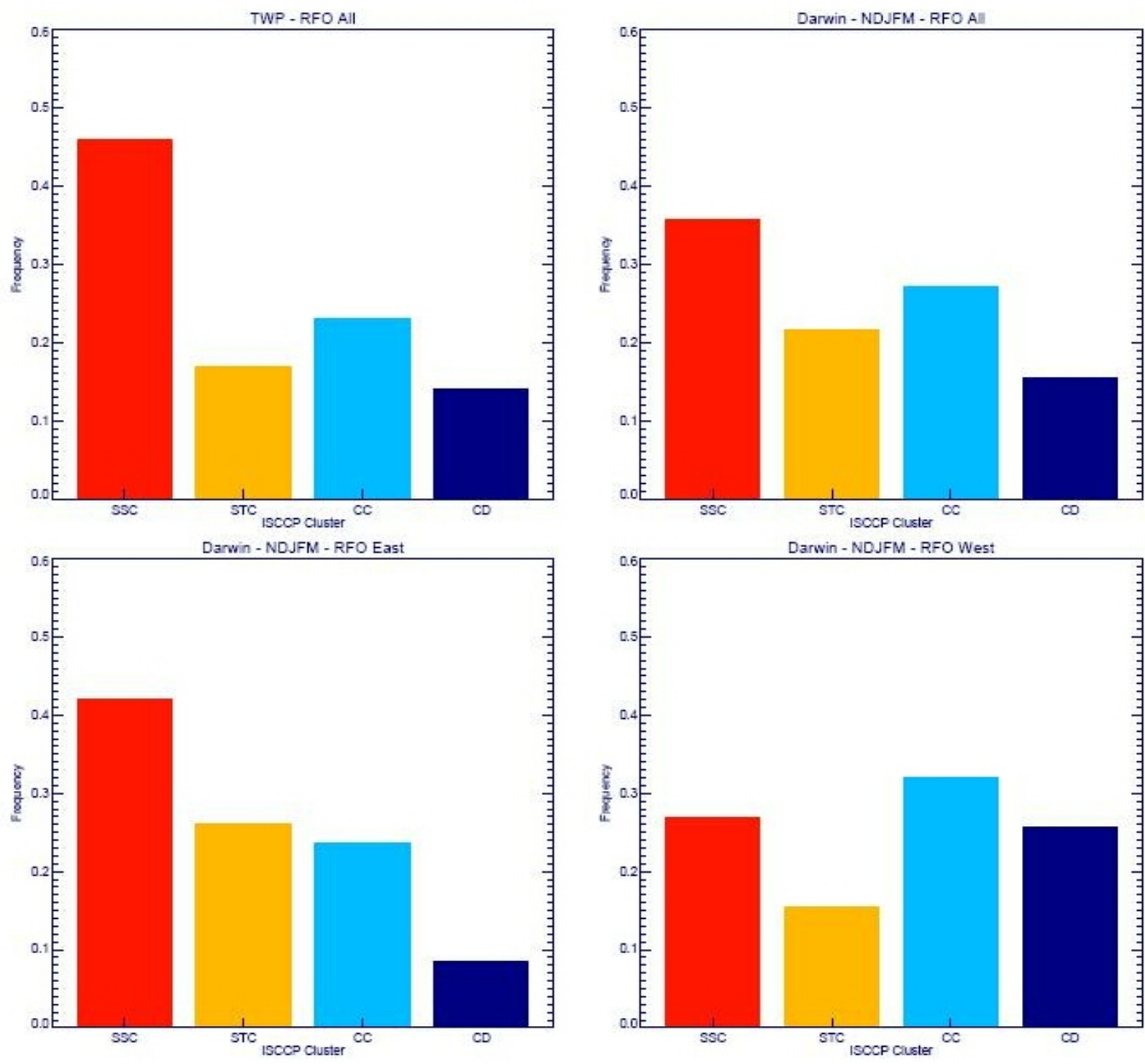

Figure 2. Relative frequencies of occurrence of the ISCCP cloud regimes. Top Left: TWP 1999-2000; Top Right: Darwin NDFJM 1999-2000; Bottom Left: Darwin NDJFM 1999-2000 easterly wind at 700 hPa; Bottom Right: Darwin NDFJM 1999-2000 westerly wind at $700 \mathrm{hPa}$.

particle habit (Heymsfield et al. 2002). It is critical that we create a particle habit-ice water content (IWC)-size spectrum dataset that spans all genre of tropical cirrus from thick anvils near their convective sources to cirrus at various stages of their lifecycle. Aircraft deployed during TWP-ICE will use a combination of in situ microphysical instruments as well as remote sensors (lidar, radar, and radiometers) with both upward and downward views to obtain this dataset (e.g., Figure 3).

In addition to developing a database of microphysical observations, there are a number of more specific issues related to cloud properties. For example, during Egrett Microphysics Experiment with Radiation Lidar and Dynamics (EMERALD)-2 and CRSYTAL-FACE, convection was continental/coastal in nature. It will be interesting to compare cloud microphysical properties under those conditions with those obtained under monsoonal conditions during TWP-ICE where the cloud condensation nuclei (CCN) characteristics are expected to be quite different. 

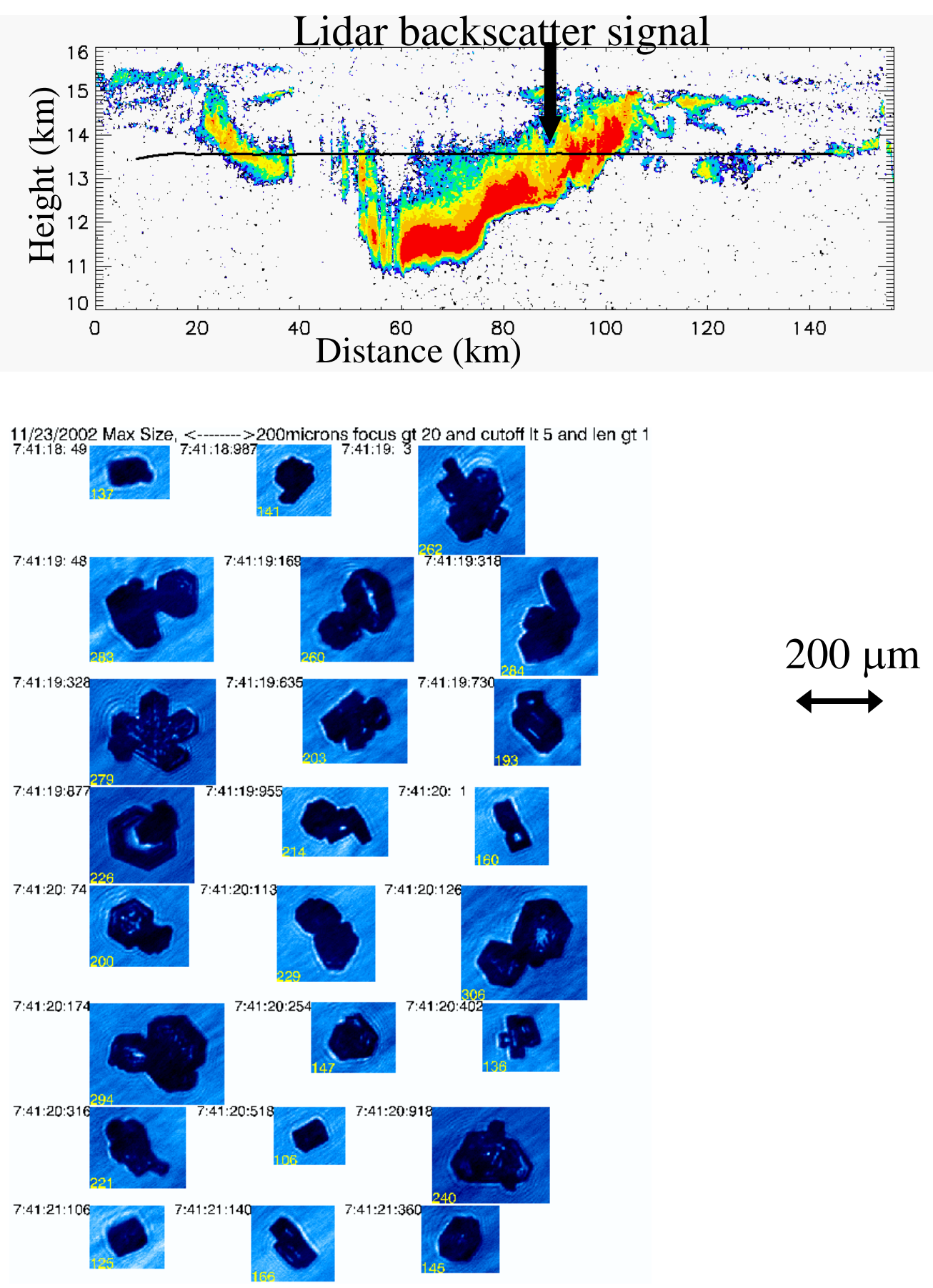

Figure 3. A cross section of the lidar backscatter returns and the in situ data from the cloud particle imager. The solid line marks the Egrett height during the stacked flight and the arrow refers to the position when these ice crystal images were collected (courtesy Jim Whiteway). 


\subsection{Evolution of Cirrus Microphysics}

Another point of interest is determining at what stage particle habits evolve from injection habits (i.e., those particles that were nucleated in the convective updraft) to particle habits representative of self maintaining cirrus clouds. The ring of radiosonde stations around the Darwin facility will provide a means to determine the large scale horizontal divergence and vertical motion in the vicinity of Darwin. In the early stages of an anvil's lifetime, its properties are determined by the vertical motion in the convective cell that formed the anvil. However, it is expected that at some point, the large-scale vertical motion at cirrus altitudes, roughly 10-15 km, will play a significant role in determining the longevity of the cirrus layer. It is further expected that the microphysical properties of the aged, potentially selfsustained, cirrus layer will be different than the newly formed anvil. Observing the transition between these modes and the microphysical properties of each would aid the parameterization of tropical cirrus.

Using the radiosonde network to define the horizontal divergence within the study area, we will attempt to calculate the large-scale vertical motion and humidity in the upper troposphere to show that the longevity of cirrus anvil shields and isolated cirrus respond to this vertical forcing by either persisting longer in ascent or decaying more rapidly in descent.

Questions associated with the transition from the convective outflow to the self-sustaining cirrus layer include the following:

1. Does this transition occur within a cloud layer or are self-maintaining cirrus more often physically separate from the convective outflow?

2. Can we determine from ground-based data when these different classes of cloud exist above the ground instruments?

3. Are there large scale controls of this transition such as a sufficiently humid environment, some amount of large-scale ascent, or the formation and maintenance of unstable layers in the upper troposphere?

A combination of aircraft measurements on long flights $(\sim 5 \mathrm{~h})$ along with vertically pointing remote sensing retrievals and cloud profiling measurements from the centimeter radars at Darwin and Gunn Point will provide the means to address these questions. Documenting this transition and what factors are related to it will ultimately be a significant contribution to our understanding of tropical cirrus.

\subsection{Effect of Convective Strength on Anvil Properties}

Doppler radar measurements will provide estimates on convective strength, as defined by the height of the convection and the intensity of the radar echoes, for cells in the Darwin area. By sampling the microphysical properties of anvils formed by cells with a range of intensities, the influence of convective strength on anvil microphysics can be examined. It is likely that the composition of the anvil will change significantly in its early stages of development as the largest particles fall out. This evolution of anvils can again be studied for a variety of convective systems. It may also be that factors such as boundary layer aerosol content or other factors may have an influence on cirrus outflow properties. It will therefore be of interest to study clouds over the continent and over the Timor Sea. 


\subsection{Transparent Cirrus Layers}

Thin cirrus clouds located near the tropical tropopause layer (TTL) in the TWP region occur frequently, can persist for several days, and extend spatially over large distances. Tropopause cirrus primarily occurs detached from deep convection. The primary mechanism that has been identified as a possible contributor to the formation of these tenuous cloud layers is in situ generation by large-scale dynamical ascent (Jensen et al. 1996). Tropical cirrus clouds are also linked to the downward phase propagation of Kelvin waves from the lower stratosphere into the upper troposphere (Boehm and Verlinde 2000). Since the primary source of water vapor in the upper troposphere is injection by deep convective systems, there is clearly a link between tropopause cirrus and deep convection. However, the actual mechanism that initiates the nucleation of ice crystals is still uncertain. Although the net radiative heating of these cirrus clouds is only a few degrees Kelvin, due to their large spatial extent and proximity to the TTL, these clouds will have a significant impact on the radiation budget (Comstock et al. 2002). Understanding the processes important to the formation and persistence of tropopause cirrus will help properly represent these clouds in global climate models.

The primary questions related to tropopause cirrus that potentially can be addressed during the Darwin 2006 experiment are as follows:

1. How does large-scale vertical motion influence the formation and persistence of tropopause cirrus?

2. What are the roles of gravity and Kelvin waves in cirrus formation?

3. What are the thermodynamic conditions in tropopause cirrus layers? This would include temperature, water vapor mixing ratio, wind speed, and direction (both vertical and horizontal).

4. What is the temperature structure in the upper troposphere and lower stratosphere?

5. What are the microphysical properties of tropopause cirrus IWC, particle size, number concentration, and particle habit)?

6. When and where do tropopause cirrus form in relation to deep convective systems?

7. The Darwin 2006 experiment can help to answer some of these questions. Ground-based and airborne lidar observations will be useful for determining when transparent layers are present as well as providing the vertical structure of these layers. In situ and remote sensing observations from aircraft will provide detailed microphysical information along with the thermodynamic and dynamic structure of the tropopause layer. Radiosonde observations will also be important for determining large-scale dynamical forcing of these clouds.

\subsection{Verification of Remote Sensing}

Another important component of the experiment will be the collection of in situ data to verify the microphysical retrievals of both the cirrus and rain. Remote measurements of cloud microphysics and rain drop size distribution (DSD) have been performed for several years using combinations of wind profiler radar and polarimetric radar (DSD's) as well as cloud radar and lidar (cirrus). ARM data and 
algorithms have been used to provide statistics of cirrus effective radius as various locations, which show dramatic geographical variation. However, in situ validation has been sorely lacking, particularly in the tropics. Extensive modeling of the measurements has been performed, but few in situ measurements are available to validate the measurements. Since these are key elements of the ARM strategy for all the sites, verification of the remote sensing retrieval remains an extremely important issue for the entire ARM Program.

Therefore, it will be important to gather as much data over the ground site as is reasonable. However, creating scatter plots of retrieved versus observed IWC or observed versus retrieved particle size will not be the sole goal of this objective. It is highly unlikely that a statistically significant scatter plot could be created from the approximately ten missions that will be conducted during the 28-day period. More important issues for validating ground-based remote sensing retrievals are to validate the assumptions in the algorithms (the shape of the particle size distribution and the various empirical coefficients that are embedded in all such algorithms). The Proteus will play an important role in addressing these sampling issues. This aircraft can be viewed as a downward-looking ARM site complete with the essential active remote sensors. Operating away from the central site but within the sounding network would then still produce significant validation opportunities and meet the other objectives of gathering as much quality cloud data as possible.

A subsidiary objective will be measurements along extended legs parallel with the wind to address issues of representativeness of the profile measurements by the MMCR/MPL/Commonwealth Scientific and Industrial Research Organization (CSIRO) lidar.

By the 2006 experiment, there should be a new suite of satellite-borne active remote sensing instruments flying as part of the A-Train, the next phase of the National Aeronautics and Space Administration's (NASA's) Earth Observing System. Instruments will include the Cloud Satellite (CloudSat) millimeter radar, Cloud-Aerosol Lidar and Infrared Pathfinder Satellite Observations (CALIPSO) satellite, and a cloud lidar. Overpasses of the Darwin region by these instruments will be relatively infrequent but there are likely to be at least one or two opportunities to underfly the A-Train observers. For ARM to ultimately contribute to the global change problem, a link will need to be made between the continuous temporal nature of the ARM data at a few locales to the spatially continuous satellite data. Therefore, it is in ARM's interest to assist in validating key satellite-derived geophysical parameters. A reasonable effort should, therefore, be made to underfly the A-Train satellites whenever practical. Flights will be dedicated to overflying the ARM site for extended periods. This will allow all the above objectives to be addressed.

\subsection{Modeling}

The representation of clouds and convection in numerical models, in particular in those applied in numerical weather prediction (NWP) model and climate studies, remains a major problem area. The experiment will provide an opportunity to study the ability of models to predict the development of tropical cloud systems from their early convective stage right through to the decaying cirrus phase. As highlighted above, the conditions expected to be encountered during the experiment will be mostly representative of oceanic convection found over large parts of the TWP. The TWP cloud regimes are of high relevance and any model improvements made based on results of this experiment will have a wide general application. 
The application of numerical models will be an integral part of the experiment. It will encompass the use of models in real-time to support the experiment activities as well as extensive modeling studies that make use of the data collected during the experiment. A small number of pre-experiment modeling studies are also envisaged. The modeling program will encompass the full range of numerical modeling systems available today to study a large number of scientific issues.

\section{Climate Models}

- Study the representation of the Australian monsoon in particular the embedded cloud structures, in selected climate models, including the Multi-Scale Modeling Framework (MMF).

- Repeat these studies after improvements based on the experiment have been implemented.

\section{Climate Models Applied in NWP Mode (CAPT)}

- Repeat the climate model studies using short-range forecasts made with the same climate model, including the MMF, in the CAPT framework.

- -Study the ability of the model to predict the monsoon evolution in the short range.

\section{Global and Regional NWP}

- - Study the representation of clouds and convection under monsoon conditions by evaluating model forecasts using data collected during the experiment.

- Study the ability of the models to predict the monsoon evolution in the short and medium range.

- Study the impact of the additional observations taken during the experiment on forecast performance.

- Investigate the use of global and regional ensemble prediction systems for forecasting in tropical monsoon conditions.

- Support the experiment through real-time forecasts.

\section{High-Resolution Local NWP}

- Study the ability of the models to simulate details of the structure of the observed cloud systems.

- Evaluate the use of very high-resolution NWP in forecasting tropical monsoon conditions.

- Support the experiment through real-time forecasts.

\section{Cloud-Resolving Models (CRMs)}

- Study the ability of CRMs to reproduce the complex structures encountered in monsoon conditions. 
- Evaluate the models' predictions of clouds and their radiative properties through extensive use of the collected data.

- Evaluate the models representation of the main convective structures encountered in the experiment.

- Study the role of the complex topography on the evolution of monsoonal cloud systems.

- Provide additional data for the evaluation of SCMs.

\section{Single-Column Models (SCMs)}

- Evaluate the representation of clouds, convection, and radiation in simulations of monsoon convection.

- Serve as the main vehicle for model development through evaluation of proposed model improvements.

- Provide a link to the climate model and NWP studies.

To support this ambitious modeling program, it is necessary to take additional observations as they are usually taken during SCM intensive operational periods (IOPs). Those are additional (in space and time) radiosonde measurements as well as surface flux measurements over a period of at least 3 weeks. The variational technique (Zhang et al. 2001), in conjunction with the Bureau of Meteorology (BoM) operational regional model, will be used to analyze the data and provide forcing datasets for CRM and SCM simulations to be carried out in the Cloud Parameterization and Modeling Working Group. The in situ and remotely sensed data gathered by both aircraft and intensive ground observations will be used in the validation of the model simulations. It is furthermore anticipated that combining the variational analysis results with the data gathered extensively by the rain radars (both Dual-Doppler and C-POL) can aid in estimating hydrometeor advection.

Several additional scientific issues will arise from the need to derive forcing datasets for CRM/SCM studies. Those include:

- the first application of the ARM variational analysis framework to tropical conditions.

- the evaluation of the ability of current NWP analyses to represent large-scale forcing in the tropics.

- the use of the available radar and satellite data to estimate hydrometeor advection.

\subsection{Documenting the Convective Cloud Evolution}

The cirrus clouds that provide the main focus of the experiment are strongly linked to the convective activity in the study area. It is therefore necessary to document in fine detail the evolution of the convective cloud systems in the monsoonal environment. This will be achieved through combinations of ground-based radar, airborne radar and lidar and in situ measurements. The dual Doppler radars along with the polarimetric microphysical classifications will provide the precipitation fields and circulations within the clouds. In situ measurements of the inflow region and boundary layer structure will describe the environment in which the storms initiate and evolve while airborne remotely sensed data will provide the resulting cloud structure in fine detail. This is a highly synergistic combination of instruments. The 
aircraft will also be carrying lidar and radar systems that will allow detailed observations through selected cross sections of the storms. In situ data from the high-flying aircraft will further document the impact of the convection on the near environment.

Keenan and Carbone (1992) (hereafter KC) describe the morphology of convective systems in the vicinity of Darwin during the monsoon as well as during the monsoon break periods and the transition seasons. The primary focus of the Darwin experiment will be on monsoon convection. Convection during active monsoon periods tends to be widespread, with complex organization and less extremely intense convection than the build up and break periods. There are often extensive regions of stratiform clouds.

Monsoon convection exhibits a diurnal cycle with the maximum in activity tending to occur at night (should show this using precipitation data or radar composites). The origin of this nocturnal maximum is still uncertain and several ideas have been presented (summarized by Nesbitt and Zipser [2003]). For example, one possibility is radiative destabilization of the boundary layer at night. The sounding and radiation measurements from the ship may be used to address this question. Because of the nocturnal maximum it will be desirable to perform some aircraft flights at night or in the early morning.

While the experiment will be held during the active monsoon period, there will likely be break periods where the environment reverts to conditions more characteristic of the transition season than the monsoon. Break period convection, in comparison with monsoon convection, is more intense and organized. It tends to exhibit an afternoon maximum and is often associated with the sea breeze. While the monsoon convection provides an opportunity of studying convection with characteristics that emulate the tropical oceans, convection during these break periods will be more representative coastal convection in the maritime continent. In fact, convection over the Tiwi Islands (a pair of islands to the immediate north of Darwin with a total length of approximately $150 \mathrm{~km}$ ), is a frequent occurrence during break periods (KC) and will be a target for sampling intense coastal convection during the breaks. Figures 4 and 5 illustrate two examples of convection during a monsoon and a break period. The storm movement in the monsoon case is complex. There is a slowly moving northward line element aligned east-west, but the apparent segment that is aligned towards the south-west was aligned along the direction of its movement and was moving to the northeast. This complexity illustrates some of the challenges for the aircraft operations. However, this complexity needs to be understood. The break-season case (Figure 5) shows a more "standard" squall line that is oriented normal to its movement. The convection in the break case is deeper and the regions of high reflectivity extend much higher.

\subsection{Impacts of Convection on the Environment}

The high altitude aircraft all have the capability of making good state measurements. This will allow the study of the layers immediately above and below the cirrus. There has been some indication that sublimation of the ice has significant thermodynamic effects in the sub cloud layer. This in turn will affect the turbulence and subsequent entrainment/detrainment in the sub cloud layer. The high flying aircraft also carry high quality instruments for measuring water vapor. This is vital for defining the combined ice/vapor fields in the cirrus clouds and their near environment to assess the overall impact of the deep convection and quantitatively measure the moistening associated with it.

The upper-level data will provide information on processes near the top of the cloud including wave generation, tropospheric/stratospheric exchange processes, and potentially dehydration mechanisms. 


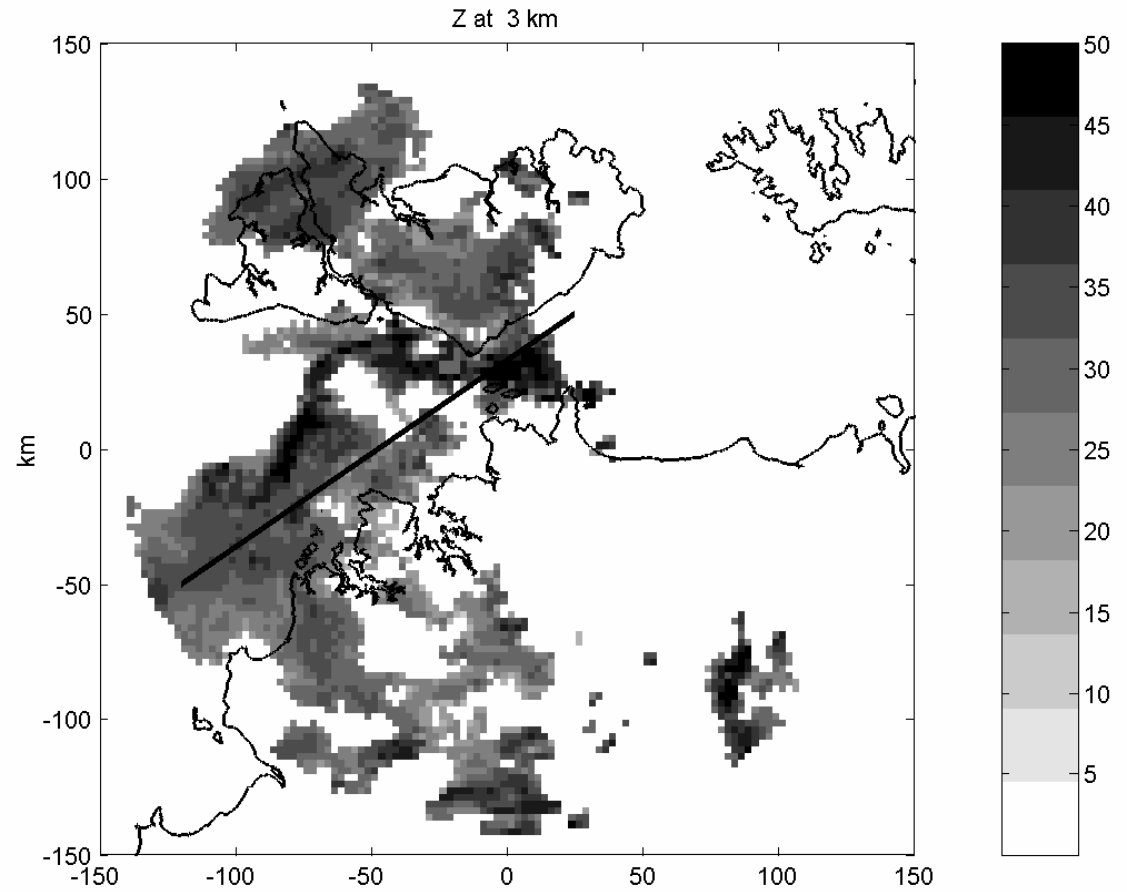

Figure 4. Plan view of the reflectivity during monsoonal convection (0700 Universal Time Coordinates [UTC] December 12, 2001).

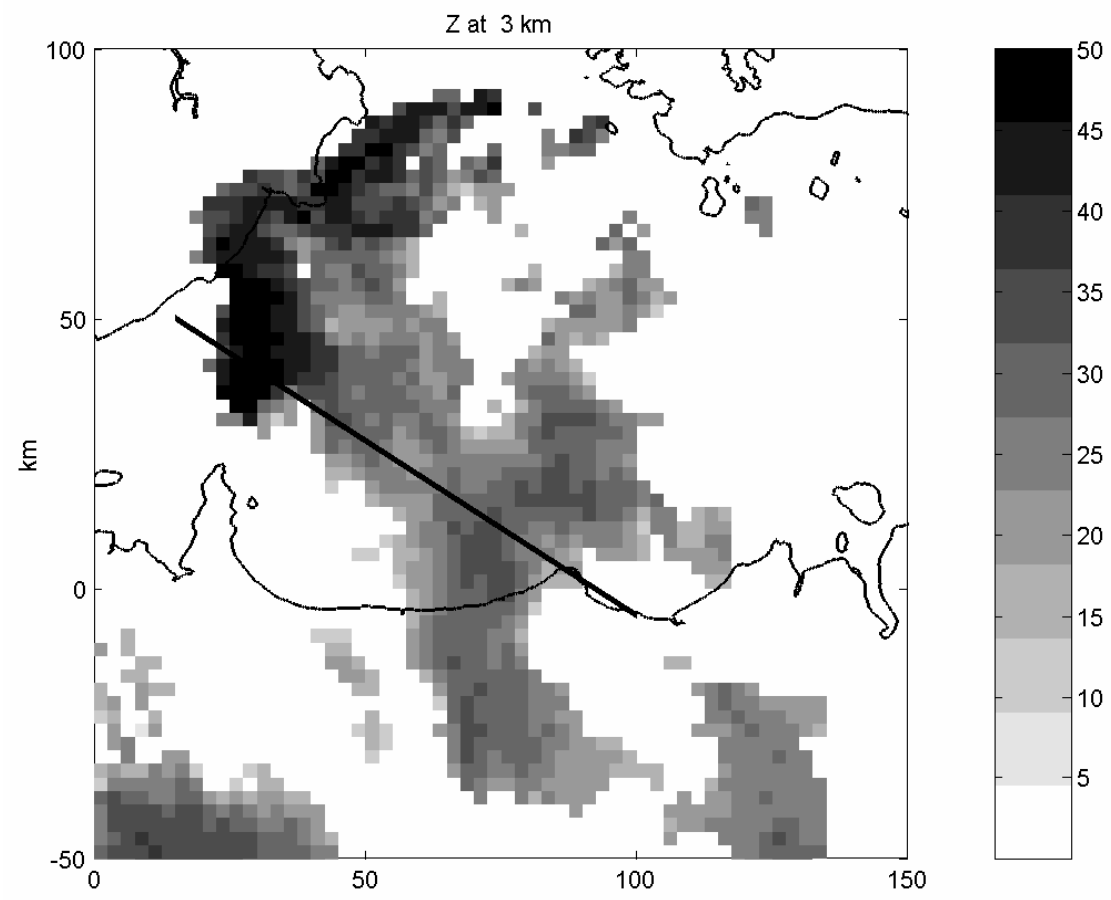

Figure 5. Constant altitude cross section through a segment of a squall line crossing Darwin in the evening of November 17, 2001. 
From a large-scale dynamics perspective, the role of cirrus in maintaining the upper tropospheric humidity structure against the overall large-scale subsidence that persists away from the convective regions is not well understood. For example:

- Do cirrus contribute significant water vapor to the large-scale tropical circulation?

- Do cirrus contribute or detract from the water vapor available to the air lofting into the Tropopause Transition Layer (TTL)?

- Do both of these processes occur simultaneously when large ice particles settle from injected ice layers, while smaller particles heat and loft to form optically thin cirrus in the TTL?

It is quite likely that the occurrence of cirrus in the otherwise clear atmosphere will turn out to induce key feedbacks to the large-scale circulation through heating and moistening (or drying) of the upper troposphere. We have an opportunity to document these feedbacks through simultaneous measurements water vapor and cloud microphysics in the upper troposphere combined with the radiative balance of the TTL.

\subsection{Relationship Between Convection and the Large-Scale Flow}

Tropical convection extending through the depth of the troposphere does not occur in isolation. During the wet season in the Darwin area it is often organized on synoptic scales associated with the large-scale structure of the active monsoon as well as with the Madden Julian Oscillation (McBride 1983; Hendon and Liebmann 1990; Mapes and Houze 1992).

During the experiment, the evolving large-scale structure of the flow will be documented in real time. Thus, at each phase of operations, experimental staff will be aware of the state of the Madden-Julian Oscillation (Hendon and Liebmann 1990), the structure and location of the monsoon trough and ITCZ (Gunn et al. 1989), advective incursions of dry air in the circulation around the heat low (Gunn et al. 1989; McBride and Frank 1999), the influence of tropical cyclones (Davidson et al. 1990) the presence of upper-tropospheric vertical motion associated with low-latitude incursions of upper-tropospheric westerly troughs (Keenan and Brody 1988), the passage of equatorially trapped wave forms in particular low-order Rossby waves (Wheeler et al. 2000) and interactions with cold-frontal incursions from higher latitudes (Danielsen 1993).

Summaries will be produced of each day's convective activity as well as of each convective event; and these will be described in the context of the low-level vorticity and divergence structure associated with the above described large-scale influences. A real-time web-based atlas will be produced summarizing each day's convective activity. This will include simple area-average indices such as mean outgoing longwave radiation (OLR), number of TBB pixels below certain thresholds, radar-derived rainfall, as well as descriptions of the organizational structure such as squall-development, mesoscale anvils and soon.

Such descriptions of the evolving structure of the flow have been an important component of previous experiments, as they provide a context for interpreting the high time and space resolution observations. They also provide an overview of the evolving flow in terms of the objectives of the experiment. 
Examples of such documentations are Mapes and Houze (1992) for EMEX, Danielsen (1993) for tropical STEP; Webster et al. (2002) for Joint Air-Sea Monsoon Interaction Experiment (JASMINE). Usually the documentations and synoptic overviews have been carried out post-experiment. Among the more obvious advantages of carrying out in real-time are that the online documentation can serve as a vehicle for recording the scientific discussions that occur in the field.

\subsection{Relationship Between the Boundary Layer and Deep Convection}

An aim of the experiment is to study the relationship between the evolution of a convective system through its life cycle and the simultaneous evolution of the convective boundary layer. A related aim is to document the evolution of the convective boundary layer through the diurnal cycle. It is presupposed that the diurnal evolution will have two differing characters depending on whether the ambient flow is lowerlevel westerly, viz monsoon conditions, as distinct from low-level easterly/break-conditions. This supposition, however, will not affect experimental design or measurement strategy, other than to ensure sampling in both regimes.

The motivation for having this as an experimental objective is the emphasis in the ARM Program on improving the parameterization of deep convective clouds in numerical models, particularly climate models. Formally, the parameterization problem is that of expressing the convective sources and sinks as functionals of the primary large-scale dependent variables (wind, temperature, moisture content, geopotential height). Current parameterization schemes are fundamentally dependent on the values of second-order or derived functions of these primary dependent variables in the sub-cloud layer. In the most elemental sense, mass-flux models require a moisture budget of the sub-cloud layer to initialize the cloud-base mass flux. Deep-tropospheric adjustment models (e.g., Betts and Miller 1986) and quasiequilibrium models (Arakawa and Schubert 1974; Emanuel 1991) require a representative sub-cloud or boundary layer thermodynamic state as a state function for the equilibrium profile. Both Convective Available Potential Energy (CAPE)-based and moisture-convergence closure schemes are fundamentally dependent on the numerical values of sub-cloud properties.

As a simple example, most convection schemes require boundary layer convergence as a trigger (or "turnon" condition); however, there is evidence that this is not the case during the mesoscale-subsidence dominated final stages of the life-cycle of a convective complex (Frank and McBride 1989; Mapes and Houze 1995).

Despite the importance of the sub-cloud layer, there has been little emphasis on its evolution in tropical convection experiments. It is well documented that ambient soundings have a convective inhibition layer of low-level negative CAPE that must be overcome by mesoscale vertical motions or possibly through the destabilization by non-precipitating and cumulus-congestus clouds. There is little published information available, however, on the evolution of the convective inhibition layer as the convection develops.

Using AMEX soundings, McBride and Frank (1999) demonstrated a large variation in CAPE as a function of height of origin of updraft air, with CAPE based on surface air having close to zero correlation with CAPE from air parcels originating at $900 \mathrm{hPa}$. A related finding was that CAPE is much smaller during active convective periods than during suppressed or break conditions. McBride-Frank's explanation of this was that during disturbed conditions portions of the boundary layer are recovering wake regions containing stable air and that these are intermittently sampled by the surface and radiosonde 
reports. Thus the convective updrafts would still be feeding on high CAPE air originating from the moist and warm boundary layer, occurring either in the undisturbed portions of the radiosonde array (or grid box), or in the boundary layer air which has been dynamically lifted by the undercutting cold, dry wake regions. This experiment will be able to extend these studies with both higher resolution sounding data so that the diurnal cycle is much better sampled, and will include concurrent radiation measurements at the sounding sites and a network of surface flux observations. The boundary layer aircraft data will be used to shed light on some of these issues.

Addressing these and related questions are fundamental to the development and refinement of both the theory of convective large-scale interactions and of practical cumulus parameterization schemes for models. The primary data platform for addressing these issues will be the high vertical resolution temperature, moisture and pressure sensors of the six radiosondes constituting the measurement array in Figure 6. Line integral techniques (as described in McBride et al. 1989) will be used to provide high vertical resolution profiles of both vertical velocity and moisture convergence through the depth of the convective boundary layer. The horizontal and temporal displacements of the sondes through their ascent will be taken into account such that maps will be produced four times per day of primary boundary layer variables. Examples would be saturation point properties of surface air (see Betts 1982) of air representative of the mixed layer of air at $900 \mathrm{hPa}$ and of the convective inhibition layer. Similarly, maps at 6-h time resolution will be produced of the lifting condensation level (LCL) of surface air and mixed layer air

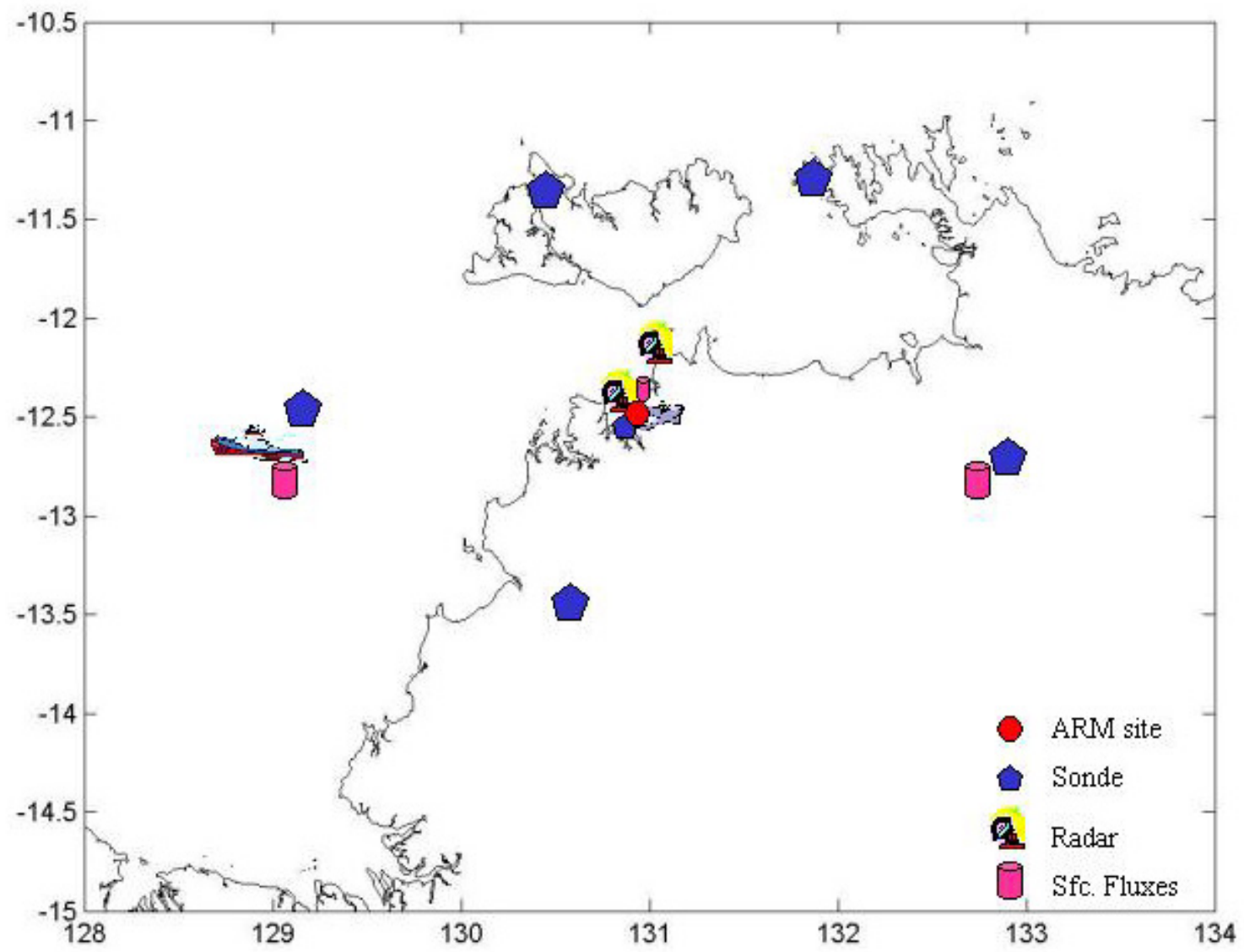

Figure 6. Location of main operations and the additional measurement sites (tentative). 
and of indices describing the vertical structure of the boundary layer, including properties of the superadiabatic constant flux layer, when and if it is present under developing tropical cumulonimbus convection.

These maps will superpose on radar imagery at each observation time in an attempt to match cloud parcel properties to updraft air. To the authors' knowledge, precedents for this type of analysis using radiosondes do not exist in recent times; however, early forms of these techniques were developed by Betts and collaborators in the Venezuelan International Meteorological and Hydrological Experiments (VIMHEX) in the 1960s and early 1970s (see e.g., Betts 1973; Betts et al. 1976; and Miller and Betts 1977) and using tethered balloon data by Fitzjarrald and Garstang (1981) in Global Atmospheric Research Program's (GARP) Atlantic Tropical Experiment (GATE). Aircraft data were used in AMEX-EMEX to relate subcloud air to convective updraft properties (Ryan et al. 1992). The boundary layer will be used to document the spatial variability of the boundary layer and its evolution in the vicinity.

To satisfy this aim of sub-cloud layer documentation, the vertical resolution, and the high spatial resolution (six sondes over a 200-km by 400-km array) are ideal. Higher temporal resolution would be preferred; however, the long period of the experiment ( 3 weeks) will mean that most convection situations will occur more than once. Thus, robust results should be attainable. This is a secondary but complementary use of the sonde array, its main function being to provide the full troposphere thermodynamic and dynamic state of a model gridpoint, as described above for the CRM and SCM datasets.

\section{THE GROUND OBSERVATION NETWORK}

This network makes use of the existing infrastructure with some considerable enhancements. These include a full suite of instruments on the ship and radiation measurements at the sonde launch sites.

\subsection{The Basic Network}

The basic observing network for the experiment is laid out in Figure 6. This shows the ground-based instruments in a ring centered on Darwin, a ship deployment and the aircraft platforms operating from Darwin.

\subsection{Radars and Atmospheric Radiation and Cloud Stations (ARCS)}

The BoM operates two weather radars systems near Darwin. One is fully polarimetric and the other is an operational Doppler. They have a baseline of approximately $25 \mathrm{~km}$ and have a dual-Doppler lobe over the open ocean. This combination allows the measurement of the three dimensional wind field within the precipitation region and thicker cloud region of the convective systems (Figure 7). Both radars complete a volume scan every $10 \mathrm{~min}$. This will allow the observation of the generation of cirrus within complex convective systems. Thus they provide the key baseline observations for the interpretation of the other datasets. These radars will also provide crucial data for directing the aircraft into regions of interest.

The polarimetric radar also provides a routine analysis of the microphysical habit of the hydrometeors that are detected by the radar. This classification uses a combination of the polarimetric and thermodynamic variables with a fuzzy logic approach. This product is generated in real time and is provided to 

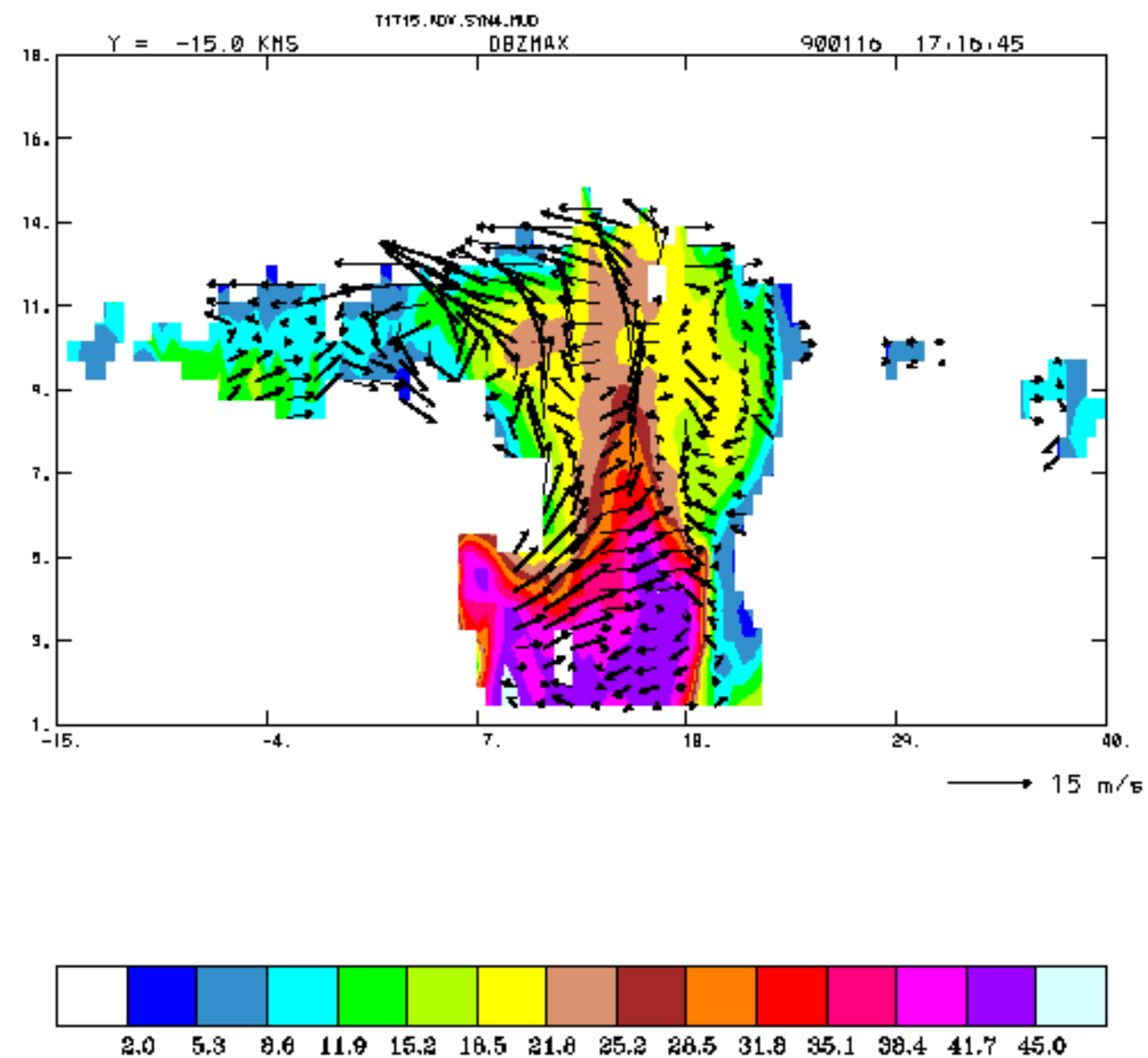

Figure 7. Example of a Dual Doppler retrieval of circulation within a storm cell. Note the direct measurement of the flow into the anvil from the main cell and the flow into the storm cell on the lower edge of the anvil. Combinations of these data with aircraft radar, lidar, and in situ measurements will be well suited to describe the impact of the convection and cirrus on the near environment.

the ARM. A sample of the data are shown in Figure 8. This is a time/height cross section of the data above the profiler site for a period of two days during the 2002-2003 monsoon. The storm tops reach to the tropopause, but there is a rapid drop-off in reflectivity with height. No hail is produced, as is often the case in coastal and continental storms. This was from a particularly active monsoon period, but does highlight the potential for rain to persist for several hours at a time, although heavy rain is relatively brief.

ARM operates a full ARCS including comprehensive radiation measurements, MPL, and 35-GHz cloud radar (Stokes and Schwartz 1994; Mather et al. 1998; Moran et al. 1998; Clothiaux et al. 1999). The Bureau operates 920- and 50-MHz wind profilers approximately $5 \mathrm{~km}$ away. An AERI instrument is being added to the Darwin ARCS site. The AERI provides continuous monitoring of the boundary layer temperature and moisture through the diurnal cycle as well as the retrieval of cloud microphysical parameters (Feltz et al. 1998). 

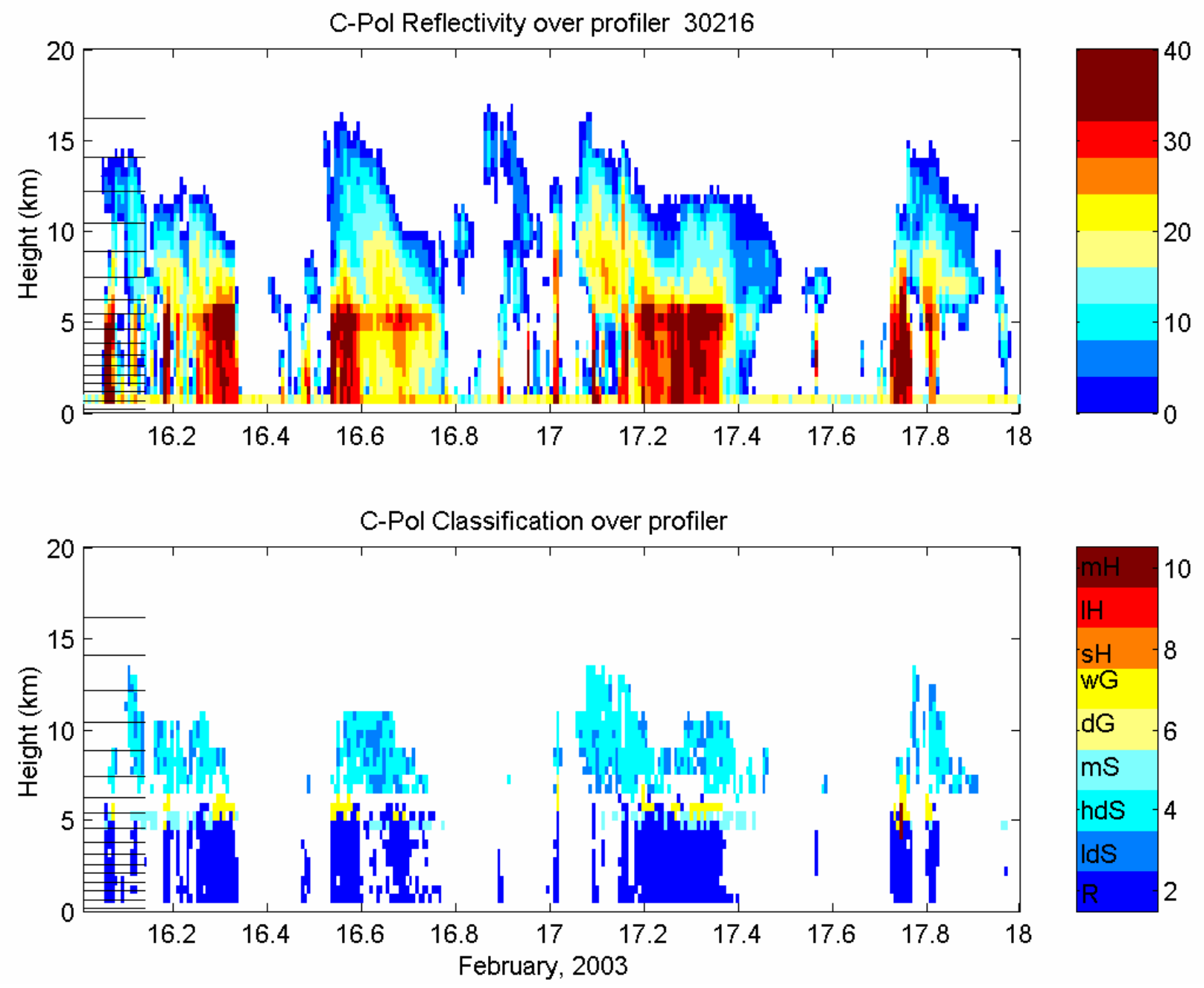

Figure 8. Time-height cross section of C-Pol reflectivity and polarimetric classification of hydrometeors. The dark blue is rain, yellow is graupel, and light blue snow.

\subsection{Radiosondes}

We propose to deploy five additional radiosonde stations around Darwin and increase the time-frequency of full sonde measurements at Darwin to that at the other stations (i.e., 3 h). Possible locations for the radiosondes are indicated in Figure 2. All sondes launched provide global positioning system (GPS) winds in addition to thermodynamic profiles. The frequent sonde launches around the central Darwin site will constrain horizontal fluxes into the Darwin region thus providing an unprecedented opportunity for modelers to test global climate model parameterizations in the tropics.

\subsection{The CSIRO Research Vessel, Southern Surveyor}

As is evident from Figure 1, an ideal set up of the sonde network requires a ship. Discussions for using Australia's National Facility Research Vessel for that purpose are currently under way. This newly commissioned ship is an oceanographic research vessel equipped with a variety of sensors for 
oceanographic and basic meteorological observations. The $66.1 \mathrm{~m}, 1594$ tonne ship is also set up to host visiting instruments and scientists.

The ship will also be important for characterizing the maritime environment, which plays a dominant role in driving monsoonal convection. Once the use of a ship has been approved, additional measurement opportunities, such as the deployment of radiation or remote sensing measurements from the ship, will emerge. These instruments would provide an opportunity to compare atmospheric parameters such as the diurnal signature of convection (and associated precipitation) and the properties of anvil cirrus over the open ocean with those observed at the Darwin site. Currently, the Pacific Northwest National Laboratory (PNNL) Atmospheric Remote Sensing Laboratory (PARSL) is being considered as a source of instrumentation including a MMCR, broadband radiometers, and a microwave radiometer (MWR) for column vapor and liquid water.

It will also be important to obtain measurements of the ocean structure. The ship will provide measurements of temperature and salinity a few meters below the surface. A towed thermistor could be used to get the ocean temperature immediately below the surface. A conductivity, temperature, and depth (CTD) package could further be used to provide profiles of temperature and salinity. Ideally, these measurements of ocean thermal/salinity structure should be made at several locations as spatial variability is likely to be important; however, this will likely not be possible. Measurements of surface fluxes including radiation, latent heat, and sensible heat are also being planned for the ship.

\subsection{The Pacific Northwest National Laboratory (PNNL) Atmospheric Remote Sensing Laboratory (PARSL)}

PARSL is a mobile atmospheric observing system with a suite of instruments that closely matches those found at the tropical Pacific ARCS sites. Passive instruments include broadband radiometers for monitoring the surface radiation budget, narrowband radiometers for retrieving cloud and aerosol properties, and a MWR for observing the integrated column amounts of water vapor and liquid water. Active instruments include a multi-channel lidar and two millimeter cloud radars. The PARSL lidar includes lasers operating at $532 \mathrm{~nm}$ and in the ultra-violet (UV). Each wavelength includes dual polarization. PARSL includes a pair of millimeter wavelength Doppler radars operating at $94-\mathrm{GHz}$ and 35-GHz. These radars provide vertical profiles of cloud properties including particle size.

There are several motivations for operating the equivalent of the ARM ARCS suite of instruments on the ship. These include issues related to potential differences in cloud properties between the oceanic and coastal environment and the goal of operating aircraft over a surface site.

Convection at Darwin closely resembles convection over the ocean during the active monsoon periods, but this is not true during break periods. Therefore, the oceanic site would likely provide a more uniform sampling of maritime convection.

Upper level winds are likely to flow from the Australian continent out over the Timor Sea where the ship will be stationed. The ship could be positioned such that the upper level winds would advect cirrus from Darwin to the ship. Thus, it would be possible to observe a cirrus layer from the surface at two points separated by approximately $100 \mathrm{~km}$. This would provide a means of studying cirrus evolution. 
One of the experiment goals is to obtain in situ observations of microphysical properties over surfacebased remote sensors to validate and improve microphysical retrieval algorithms. Maintaining a second site will increase the likelihood of finding favorable cloud conditions for such a comparison. While it is not expected that there will be difficulty in obtaining permission to fly over the Darwin site, because there is relatively little air traffic into Darwin, it will nevertheless be easier to arrange missions over the ocean, well away from the city.

\subsection{Surface Flux Measurements}

This field experiment will have unprecedented access to surface flux measurements across the domain that will provide area-mean as well as landscape-specific values of heat and moisture input to the atmosphere. These measurements will be invaluable for modeling purposes as well as budget studies. We are fortunate that the TWP-ICE follows immediately upon the Savanna Fire Experiment (SAFE) that concludes in December 2005. Equipment arrays and towers established by the Monash University group (Tapper, Beringer) for SAFE will be made available for this experiment.

In addition to the open ocean ship-borne measurements made west of Darwin by CSIRO Land and Water (Bradley) and Environmental Modeling Solutions (Sanderson), the Monash group will establish flux measurement sites over inshore waters (channel marker, outer Darwin Harbour), at Darwin Airport, at Howard Springs (35 km south of Darwin), at the Adelaide River crossing on the Stuart Highway (approximately $100 \mathrm{~km}$ south of Darwin), and also at the Adelaide River crossing on the Arnhem Highway near Jabiru (approximately $200 \mathrm{~km}$ east of Darwin). These locations have been chosen as being representative of a range of landscape types in the Darwin area, but may be moved if more representative sites are found. Upward and downward directed radiation measurements will be made at some of these locations (Table 1). It is proposed to regularly use a low-flying research aircraft (Cessna) to take surface flux measurements to establish the representativeness of the fixed sites for the domain average, as well as to check on the absolute accuracy of measurement.

For the modeling it is important to have knowledge of both the area mean and the separate land/sea characteristics. Thus, we will have representative flux measurements over much of the domain. This will be further explored with low flying aircraft data.

\section{AIRCRAFT AND INSTRUMENTS}

\subsection{The ARM UAV (Proteus)}

The Proteus piloted aircraft was designed and built by Scaled Composites, Inc., and is currently also operated by them. It is a twin turbofan high altitude platform with a crew of two and a seat for one additional person. It has a wingspan of $78 \mathrm{ft}$, gross weight of 12,500 lb, fuel capacity of $5500 \mathrm{lb}$, can carry a $6900 \mathrm{lb}$ podded payload, and supply $20 \mathrm{~kW}$ payload power. With the ARM-Unmanned Aerospace Vehicle (UAV) payload pod, the Proteus has a service ceiling in excess of $50 \mathrm{kft}$ and endurance in excess of $20 \mathrm{~h}$. The maximum mission indicated air speed is $160 \mathrm{kts}$ or Mach 0.6 true air speed yielding a potential mission radius or $3000 \mathrm{~nm}$. It is now equipped with a comprehensive instrument suite described below. The proteus carries an extensive suite of instruments for in situ sampling of cloud microphysical characteristics and remote sensors of the cloud structure with lidar and cloud radar as well as the 
thermodynamic structure with the HIS instrument. It also makes good state measurements in situ. The instrument list is shown in Table 2 and described more fully in Appendix A.

\begin{tabular}{|c|c|c|}
\hline Location & Nature of Landscape & Instrumentation/Measurements \\
\hline Darwin Harbour & Inshore waters & $\begin{array}{l}\text { 3D eddy covariance (sensible, } \\
\text { latent heat flux, } 20 \text { min av.) } \\
\text { Pygeometers/pyranometers/net } \\
\text { radiometer (net radiation, upward } \\
\text { and downward directed short and } \\
\text { longwave radiative fluxes) } \\
\text { A-band and water vapor band } \\
\text { spectrometer (AWS) (basic } \\
\text { meteorological observations) }\end{array}$ \\
\hline Darwin Airport & Semi-urban grass/scrub & $\begin{array}{l}\text { Bowen ratio system (sensible, } \\
\text { latent and substrate heat fluxes, } \\
20 \text { min av) } \\
\text { Net radiometer (net radiation) }\end{array}$ \\
\hline Howard Springs & $\begin{array}{l}\text { Dense savanna woodland to } \\
20 \text { metres }\end{array}$ & $\begin{array}{l}\text { Tower mounted 3D eddy } \\
\text { covariance (sensible, latent, } \\
\text { substrate heat flux, } 20 \text { min av.) } \\
\text { Pyrgeometers/pyranometers/net } \\
\text { radiometer (net radiation, upward } \\
\text { and downward directed short and } \\
\text { longwave radiative fluxes) } \\
\text { AWS (basic meteorological } \\
\text { observations) }\end{array}$ \\
\hline Adelaide River (South) & Open savanna woodland & $\begin{array}{l}\text { Bowen ratio system (sensible } \\
\text { latent and substrate heat fluxes, } \\
20 \text { min av) } \\
\text { Net radiometer (net radiation) } \\
\text { AWS (basic meteorological } \\
\text { observations) }\end{array}$ \\
\hline Adelaide River (East) & $\begin{array}{l}\text { Dense savanna } \\
\text { woodland/rainforest pockets to } \\
20 \text { metres }\end{array}$ & $\begin{array}{l}\text { Tower mounted 3D eddy } \\
\text { covariance (sensible, latent, } \\
\text { substrate heat flux, } 20 \text { min av.) } \\
\text { Net radiometer (net radiation) } \\
\text { AWS (basic meteorological } \\
\text { observations) }\end{array}$ \\
\hline Arafura Sea (West) & Open ocean & $\begin{array}{l}\text { Bulk flux observations from RV } \\
\text { Southern Surveyor }\end{array}$ \\
\hline
\end{tabular}




\begin{tabular}{|c|c|}
\hline Measurement & Instrument \\
\hline Solar spectral irradiance & Solar Spectral Flux Radiometer \\
\hline \multirow{2}{*}{$\begin{array}{l}400-1050 \mathrm{~nm} \\
710-800 \mathrm{~nm} \\
1300-1500 \mathrm{~nm} \text { radiance at nadir }\end{array}$} & Spectral Radiance Package \\
\hline & Broadband Hemispheric Radiometers \\
\hline $\begin{array}{l}0.35-50 \mu \mathrm{m} \text { cloud and aerosols } \\
25-1550 \mu \mathrm{m} \text { cloud particle images } \\
\text { Liquid water content }\left(0.001-3 \mathrm{gm}^{-3}\right) \\
\text { Air speed and temperature }\end{array}$ & $\begin{array}{l}\text { Cloud Aerosol and Precipitation } \\
\text { Spectrometer (CAPS) }\end{array}$ \\
\hline Ice particles $>10 \mu \mathrm{m}$ & Video Ice Particle Sampler \\
\hline Cloud scattering optical depth & Cloud Integrating Nephelometer \\
\hline $\begin{array}{l}\text { Liquid water content } \\
\text { Total water content }\end{array}$ & Nevzorov probe \\
\hline Radar reflectivity (>42 dBZ @ 1km) & Millimeter wave radar \\
\hline Lidar backscatter & Cloud detection lidar \\
\hline $\begin{array}{l}\text { Hemispheric cloud images } \\
\text { (620-670 nm and 1580-1640 nm filters) }\end{array}$ & Diffuse field camera \\
\hline Temperature and humidity profiles & $\begin{array}{l}\text { Scanning High Resolution Interferometer } \\
\text { Sounder (S-HIS) }\end{array}$ \\
\hline Humidity and temperature & $\begin{array}{l}\text { In situ measurements frost point and } \\
\text { cryogenic hygromteres and temperature } \\
\text { probe. }\end{array}$ \\
\hline
\end{tabular}

\subsection{The ARA Egrett}

The Egrett will be carrying a suite of in situ microphysical measurements and an upward and downward looking lidar system for lidar backscatter measurements. The maximum altitude of the aircraft is approximately $13.5 \mathrm{~km}$ and will fly stacked formations. The combination of the Proteus and Egrett will allow simultaneous sampling of the upper and lower parts of the cirrus anvils as well as remote measurements.

The instrument list is shown in Table 3 and a more complete description of the ARTA aircraft is described in Appendix B.

\subsection{The ARA King Air}

The aircraft will fly at altitudes up to $5000 \mathrm{~m}$ and will be capable of flying stacked flights with the Egrett and Proteus. Instrumentation will include an elastic backscatter polarization lidar with an output of $30 \mathrm{~mJ}$ per pulse at $532 \mathrm{~nm}$ and a pulse repetition frequency (PRF) of $20 \mathrm{~Hz}$. The detector uses a 10-cm telescope detecting two components of polarization relative to output using photon counting. The vertical 


\begin{tabular}{|c|c|c|}
\hline Measurement & Instrument & Institution \\
\hline $\begin{array}{l}\text { Cloud Structure } \\
\text { Water Vapour, 14-18 km }\end{array}$ & Lidar & York University \\
\hline Cloud Particles & $\begin{array}{l}\text { ???????: } \\
1-47 \mu \mathrm{m}\end{array}$ & MSC \\
\hline Cloud Particles & $\begin{array}{l}\text { SPEC Cloud Particle Imager } \\
10-1550 \mu \mathrm{m}\end{array}$ & MSC \\
\hline $\begin{array}{l}\text { Water Vapour } \\
0-14 \mathrm{~km}\end{array}$ & Drop Sondes & MSC \\
\hline $\begin{array}{l}\text { Water Vapour } \\
\text { In situ }\end{array}$ & $\begin{array}{l}\text { Tunable diode laser (TDL) } \\
\text { spectrometer }\end{array}$ & $\begin{array}{l}\text { UWA } \\
\text { with York University }\end{array}$ \\
\hline $\begin{array}{l}\text { Water Vapour } \\
\text { In situ }\end{array}$ & Frost point hygrometer & $\begin{array}{l}\text { DLR } \\
\text { with York University }\end{array}$ \\
\hline Dynamics/Turbulence & $\begin{array}{l}\text { BAT probe } \\
\text { Rosemount Probe }\end{array}$ & $\begin{array}{l}\text { ARA } \\
\text { with York University }\end{array}$ \\
\hline Temperature & $\begin{array}{l}\text { Rosemount PT100 } \\
\text { BAT probe }\end{array}$ & $\begin{array}{l}\text { ARA } \\
\text { with York University }\end{array}$ \\
\hline Ozone & UV photometer & $\begin{array}{l}\text { DLR } \\
\text { with York University }\end{array}$ \\
\hline \multicolumn{3}{|c|}{$\begin{array}{l}\text { ARA - Airborne Research Australia } \\
\text { BAT - Best Aircraft Turbulence } \\
\text { MSC - Meteorological Service of Canada } \\
\text { SPEC - Stratton Park Engineering Company } \\
\text { UWA - University of Western Australia }\end{array}$} \\
\hline
\end{tabular}

resolution is $30 \mathrm{~m}$ and the temporal sampling of averaging over 2.5 seconds, corresponds to horizontal distance of 250m on King Air. 94-GHz cloud radar for sampling the optically thick cirrus will also be used. The aircraft will also be instrumented with excellent in situ measurements with the Airborne Research Australia (ARA) Best Aircraft Turbulence (BAT) probes.

\subsection{The ARA Dimona}

This aircraft will be dedicated to making detailed in situ measurements in the boundary layer. Key roles will be the mapping of near surface fluxes to sample the spatial variability of the fluxes to complement the ground/ship based observations. The aircraft will also be used to sample the boundary layer structure near the developing convection. The aircraft carries turbulence probes for state measurements and has an extensive chemistry capability as well (see Appendix B).

\subsection{The NASA WB-57}

In support of its Aura validation program, NASA will contribute the WB-57 and associated instruments. The WB-57 has a ceiling of nearly $19 \mathrm{~km}$ (16-17 km early in a flight when fully loaded with fuel), a 
maximum duration of $6.5 \mathrm{~h}$, and is capable of carrying a payload of $2700 \mathrm{~kg}$. The Aura satellite is equipped with instruments for studying the chemistry of the upper troposphere and stratosphere but NASA science goals for TWP-ICE include many issues that overlap the goals outlined previously. These goals include studying the relationship between monsoonal convection and tropical cirrus and studying the properties of the tropical tropopause layer. The WB-57 will be used primarily for in situ observations of the upper troposphere. The proposed instrument payload is listed in Table 4. Of particular relevance to the ARM science goals is an extensive suite of instruments for observing cloud microphysical properties.

\begin{tabular}{|c|}
\hline Observation \\
\hline $\mathrm{T}, \mathrm{P}$ \\
\hline $\mathrm{O}_{3}$ \\
\hline $\mathrm{H}_{2} \mathrm{O}$ vapor \\
\hline $\mathrm{CO}, \mathrm{CH}_{4}$ or $\mathrm{N}_{2} \mathrm{O}$ \\
\hline $\mathrm{NO}_{\mathrm{x}}$ \\
\hline Aerosol size distribution \\
\hline $\begin{array}{l}\text { UV-vis spectrometer } \\
\left(\mathrm{NO}_{2} \text { column, BrO-HCHO) }\right.\end{array}$ \\
\hline FTIR \\
\hline Cloud/Aerosol lidar \\
\hline $\mathrm{H}_{2} \mathrm{O}$ total (CVI+alternate) \\
\hline $\begin{array}{l}\text { Clouds particle size } \\
\text { (such as VIPS,CAPS, HVPS) }\end{array}$ \\
\hline Cloud Particle habit \\
\hline Turbulence 3 -d winds \\
\hline Cloud extinction \\
\hline Outgoing Longwave Radiation and Solar Spectral Irradiation \\
\hline HNO3 \\
\hline $\mathrm{HO}_{\mathrm{x}}$ \\
\hline $\mathrm{HCl}$ \\
\hline $\mathrm{H}_{2} \mathrm{O}$ isotopes \\
\hline Whole air sampler ( $\mathrm{N}_{2} \mathrm{O}, \mathrm{CFCs}, \mathrm{CH}_{4}-\mathrm{CH}_{3} \mathrm{Br}-\mathrm{CH}_{3} \mathrm{I}$-etc.) \\
\hline $\mathrm{BrO}, \mathrm{ClO}$ \\
\hline GPS downlink, \\
\hline $\begin{array}{l}\text { CAPS - Cloud Aerosol and Precipitation Spectrometer } \\
\text { FTIR - Fourier transform infrared radiometer } \\
\text { GPS - global positioning system } \\
\text { HVPS - high volume precipitation spectrometer } \\
\text { VIPS - video ice particle sampler }\end{array}$ \\
\hline
\end{tabular}




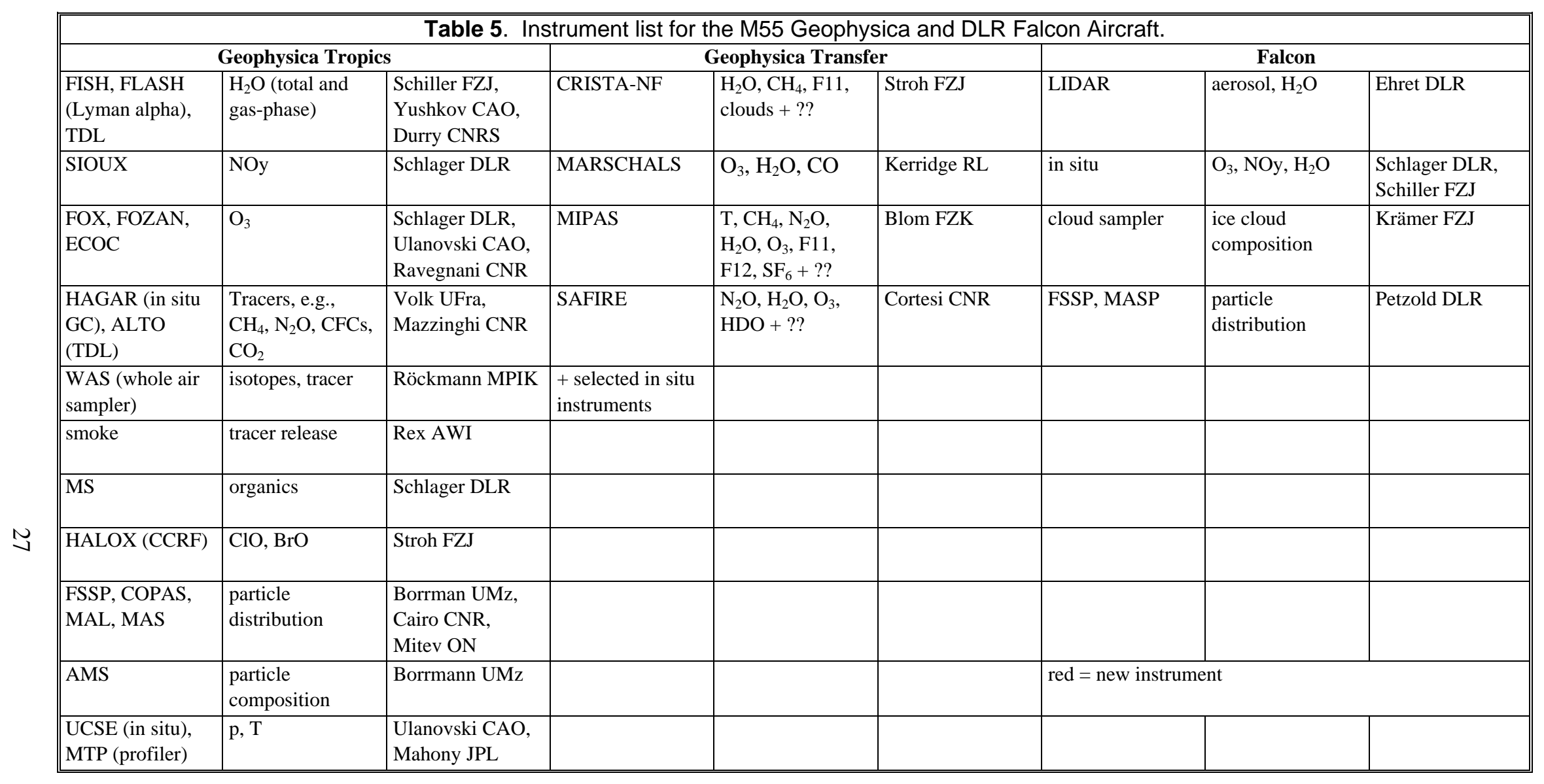




\subsection{The M55 Geophysica and DLR Falcon}

These aircraft are operated by the European Union. The M55 Geophysica is a Russian aircraft capable of flying to altitudes as high as $22 \mathrm{~km}$. This is primarily a platform for in situ observations. The DLR Falcon is equipped for good in situ measurements of state variables as well as cloud microphysics. However, it also carries an upward looking lidar system. The airspeed of the two aircraft is similar so that they usually fly stacked flight legs. The instrument lists for the aircraft is listed in Table 5.

\subsection{Flight Plans}

With multiple aircraft participating in the experiment, it is particularly important to carefully consider how the aircraft will be utilized. Several basic types of flights are being planned which address particular science goals of the experiment. These classes of flights may involve various combinations of aircraft. In most cases, there will be an emphasis on coordinating the Proteus, Egrett, and King Air in stacked legs or in otherwise patterns coupled to sample a particular system. There will also be an emphasis (except where otherwise noted) on flying within range of the Darwin region Doppler radars (150 km). The main types of flights being considered and the associated aircraft are:

Convection development. Here the focus will be on the environmental conditions leading to convection (obtained primarily by the boundary layer aircraft, sondes, and Doppler radar) and the properties of anvil associated with these systems. These flights are likely to involve all aircraft.

Mature convection/anvil evolution. Here, the focus will be on aging anvils. The experiment may be coupled with a study of convection development. The emphasis at this stage will likely not involve the boundary layer aircraft. It will likely involve stacked legs of the mid and high altitude aircraft. The need for each of these aircraft will be dictated in large part by the vertical extent of the cirrus layer. In some cases, it may be that use of only some of the aircraft in a stack would be appropriate. A further useful method will be to employ some slow spiral descents through some areas of the cirrus to document the vertical structure and variations of the microphysics with height.

Thin cirrus/upper tropospheric water. Thin cirrus, typically forming near the tropopause have been observed at the Manus and Nauru ARM sites. Sometimes these clouds are observed many hundreds of kilometers from any convective source. It is believed that these clouds are formed and maintained through dynamical lifting associated with upper tropospheric/lower stratospheric waves. It is likely that these clouds, which may be important for the TOA energy balance and for stratosphere/troposphere exchange of water vapor, have different microphysical properties than convective outflow. Therefore, there is an interest in seeking out these clouds. Sampling these clouds may require leaving the Darwin region for the deeper tropics so we expect to commit several flights to sampling the upper troposphere away from the Darwin region. Most likely, only the Proteus would be used on these missions because it would be the only aircraft potentially capable of reaching the required altitudes of $14-17 \mathrm{~km}$. The Proteus also has the longest duration making it doubly suitable for these flights away from the base region.

Surface fluxes. As the radiosondes provide a constraint on the horizontal fluxes into the Darwin region, the boundary layer aircraft, coupled with the surface flux stations, will provide a constraint on the surface fluxes of heat and radiation. The boundary layer aircraft will be flown in a variety of conditions including pre-convection, active convection, post-convection, daytime, and nighttime to sample the surface fluxes 
in a variety of conditions. Some of these flights (particularly those in active convection or during periods of convective decay) may be coordinated with the high flying microphysical sampling aircraft, but in other cases, they may involve the boundary layer aircraft alone.

Satellite validation. As previously stated, there is an interest in relating surface-based remote sensing with satellite remote sensing; therefore, there will be an effort to support validation of satellite measurements.

\section{NWP SUPPORT AND TESTING}

The Australian BoM and the European Centre for Medium-range Weather Forecasts (ECMWF) operational models will be provided in real time and for archive purposes during the experiment. These models will be used for both experiment-planning purposes and as research tools. These centers will also be evaluating the impact of the high temporal and spatial resolution soundings.

The Australian model suite will include limited area models at approximately 37-km and 15-km resolution as well as a 5-km resolution model. An experimental non-hydrostatic forecast model with resolution $\sim 1 \mathrm{~km}$ is also anticipated by the time of the experiment. The 5-km and 1-km versions of the model include explicit microphysical parameterizations carrying cloud water and ice as well as rain, snow, graupel, and vapour.

Under the existing data exchange agreement with ARM, ECMWF will provide both deterministic and ensemble prediction products in real time in support of the experiment activities. A detailed list of products will be drawn up as part of the operations plan.

The experiment will have access to the full resources of the Northern Territory Regional Forecast Office. This includes access to the real time NWP, satellite, radar, and A-band and water vapor band spectrometer (AWS) systems. The regional office will be supplying an experienced forecaster to work with the experiment team during the experiment. A website will be set up that includes a selection of satellite, NWP, and radar products for delivery to the laboratories at the airport, sounding sites, ship, and the aircraft.

\section{SATELLITE DATASETS}

It is anticipated that a number of satellite products will be utilized to define the TOA boundary and to provide independent retrievals of cloud properties. These satellite products will be integrated into the experiment design in several ways. Aircraft and ground-based remote sensors will provide important verification datasets for CloudSat and CALIPSO these two instruments are due to be launched in late 2004. Other satellite instruments that will be of great use for TWP-ICE analysis include radiometers on the Japanese geostationary multifunctional transport satellite (MTSAT)-1R (also due for launch in late 2004) and instruments on the Aqua and Terra platforms. Of particular interest on these NASA satellite platforms will be the moderate-resolution atmospheric radiance and transmittance model (MODIS) and Clouds and Earth’s Radiant Energy System (CERES), which provide retrievals of cloud properties. 


\section{REFERENCES}

Arakawa, A., and W. H. Schubert, 1974: Interaction of a cumulus cloud ensemble with the large-scale environment. Part I. J. Atmos. Sci., 31, 674-701.

Betts, A. K. 1973: A composite mesoscale cumulonimbus budget. J. Atmos. Sci., 30, 597-610.

Betts, A. K. 1982: Saturation point analysis of moist convective overturning. J. Atmos. Sci., 39, 1484-1505.

Betts, A. K., R. W. Grover, and M. W. Moncrieff, 1976: Structure and motion of tropical squall-lines over Venezuela. Quart. J. Roy. Meteor. Soc., 102, 395-404.

Betts, A. K., and M. J. Miller, 1986: A new convective adjustment scheme. Part II. Single column tests using GATE wave, BOMEX, ATEX and Arctic air-mass datasets. Quart. J. Roy. Meteor. Soc., 112, 693-709.

Boehm, M. T., and J. Verlinde, 2000: Stratospheric influence on upper tropospheric tropical cirrus. Geophys. Res. Let., 27, 3209-3212.

Clothiaux, E. E., et al., 1999: The Atmospheric Radiation Measurement Program Cloud Radar: Operational Modes. J. Atmos. Ocean. Tech., 16, 819-827.

Comstock, J. M., T. P. Ackerman, and G. G. Mace, 2002: Ground-based lidar and radar remote sensing of tropical cirrus clouds at Nauru Island: Cloud statistics and radiative impacts. J. Geophys. Res., 107(23), 4714, doi:10.1029/2002JD002203.

Comstock, J. M., and K. Sassen, 2001: Retrieval of cirrus cloud radiative and backscattering properties using combined lidar and infrared radiometer (LIRAD) measurements. J. Atmos. Ocean. Tech., 18, 1658-1673.

Danielsen, E. F., 1993: In situ evidence of rapid, vertical irreversible transport of lower tropospheric air into the lower tropical stratosphere by convective cloud turrets and by large-scale upwelling in tropical cyclones. J. Geophys. Res., 98, 8665-8681.

Davidson, N. E., G. Holland, J. L. McBride, and T. D. Keenan, 1990: On the formation of AMEX Tropical Cyclones Irma and Jason. Monthly Weather Review, 118, 1981-2000.

Emanuel, K. A., 1991: A scheme for representing cumulus convection in large-scale models. J. Atmos. Sci., 35, 1921-1933.

Feltz, W. F., et al., 1998: Meteorological applications of temperature and water vapor retrievals from the ground-based atmospheric emitted radiance interferometer (AERI). J. Appl. Met., 37, 857-875.

Fitzjarrald, D. R., and M. Garstang, 1981: Vertical structure of the tropical boundary layer. Mon. Wea. Rev., 109, 1512-1526. 
Frank, W. M., and J. L. McBride, 1989: The vertical distribution of heating in AMEX and GATE cloud clusters. J. Atmos. Sci., 46, 3464-3478.

Gunn, B. W., J. L. McBride, G. J. Holland, T. D. Keenan, N. E. Davidson, and H. H. Hendon, 1989: The Australian Summer Monsoon Circulation during AMEX Phase II. Mon. Wea. Rev., 117, 2554-2574.

Hendon, H. H., and B. Liebmann, 1990: The intraseasonal (30-50 day) oscillation of the Australian summer monsoon. J. Atmos. Sci., 47, 2909-2923.

Heymsfield, A. J., et al., 2002: Observations and parameterizations of particle size distributions in deep tropical cirrus and stratiform precipitating clouds: Results from in situ observations in TRMM field campaigns. J. Atmos. Sci., 59, 3457-3491.

Jakob, C., and G. Tselioudis, 2003: Objective identification of cloud regimes in the Tropical Western Pacific. Geophys. Res. Let., 30, 2082, doi: 10.1029/2003GL018367.

Jensen, E. J., O. B. Toon, H. B. Selkirk, J. D. Spinhirne, and M. R. Schoeberl, 1996: On the formation and persistence of subvisible cirrus clouds near the tropical tropopause. J. Geophys. Res., 101, 21,361-21,375.

Keenan, T. D., and L.R. Brody, 1988: Synoptic-scale modulation of convection during the Australian summer monsoon. Mon. Wea. Rev., 116, 71-85.

Keenan, T. D., J. McBride, G. Holland, N. Davidson, and B. Gunn, 1989: Diurnal variations during the Australian Monsoon Experiment (AMEX) Phase II. Mon. Wea. Rev., 117, 2535-2553

Keenan, T. D., and R. E. Carbone, 1992: A preliminary morphology of precipitation systems in tropical northern Australia. Quart. J. Roy. Meteor. Soc., 118, 283-326.

Keenan, T., S. Rutledge, R. Carbone, J. Wilson, T. Takahashi, P. May, N. Tapper, M. J. Hacker, S. Sekelsky, M. Moncrieff, K. Saito, G. Holland, A. Crook, and K. Gage, 2000: The Maritime Continent Thunderstorm Experiment (MCTEX): Overview and some results. Bull. Amer. Meteor. Soc., 81, 2433-2455.

Kelly, K. K., M. H. Proffitt, K. R. Chan, M. Loewenstein, J. R. Podolske, S. E. Strahan, J. C. Wilson, and D. Kley, 1993: Water vapor and cloud water measurements over Darwin during the STEP 1987 tropical mission. J. Geophys. Res., 98, D5, 8713-8723.

Manton, M. J., and J. L. McBride, 1992: Recent research on the Australian monsoon. J. Meteor. Soc. Japan, 70, 275-285.

Mapes, B., and R. A. Houze, Jr., 1992: An integrated view of the 1987 Australina monsoon and its mesoscale convective systems. I: Horizontal structure. Quart. J. Roy. Meteor. Soc., 118, 927-963.

Mapes, B. E., and R. A. Houze, Jr., 1995: Diabatic divergence profiles in tropical mesoscale convective systems. J. Atmos. Sci., 52, 1807-1828. 
Mather, J. H., T. P. Ackerman, W. E. Clements, F. J. Barnes, M. D. Ivey, L. D. Hatfield, and R. M. Reynolds, 1998: An Atmospheric Radiation and Cloud Station in the Tropical Western Pacific. Bull. Amer. Met. Soc., 79, 627-642.

McBride, J. L., 1983: Satellite observations of the southern hemisphere monsoon during Winter MONEX. Tellus, 35A, 189-197.

McBride, J. L., 1987: The Australian summer monsoon. In Monsoon Meteorology. C. P. Chang and T. N. Krishnamurti (eds). Oxford University Press, p. 203-231.

McBride, J. L., 1998: Indonesia, Papua New Guinea, and Tropical Australia, Chapter 3A of Meteorology of the Southern Hemisphere, Meteorological Monograph No. 49, American Meteorological Society.

McBride, J. L., and W. M. Frank, 1999: Relationships between stability and monsoon convection. J. Atmos. Sci., 56, 24-36.

McBride, J. L., B. W.Gunn, G. J.Holland, T. D. Keenan, N. E. Davidson, and W. M. Frank, 1989: Time series of total heating and moistening over the Gulf of Carpentaria radiosonde array during AMEX. Mon. Wea. Rev., 117, 2701-2713.

McMillan, W. W., et al., 2003: Tropospheric carbon monoxide measurement from the scanning highresolution interferometer sounder on 7 September 2000 in Southern Africa during SAFARI 2000. J. Geophys. Res., 108, doi:10.1029/2002JD002335.

Miller, M. J., and A. K. Betts, 1977: Traveling convective storms over Venezuela. Mon. Wea. Rev., 105, 833-848.

Moran, K. P., B. E. Martner, M. J. Post, R. A. Kropfli, D. C. Welsh, and K. B. Widener, 1998: An unattended cloud-profiling radar for use in climate research. Bull. Amer. Met. Soc., 79, 443-455.

Nesbitt, S. W., and E. J. Zipser 2003: The diurnal cycle of rainfall and convective intensity according to three years of TRMM measurements. J. Clim., 16, 1456-1475.

Petersen, W. A., and S. A. Rutledge, 2001: Regional variability in tropical convection: Observations from TRMM. J. Clim., 14, 3566-3586.

Platt, C. M. R., J. C. Scott, and A. C. Dilley, 1987: Remote Sounding of High Clouds. Part VI: Optical Properties of Mid-latitude and Tropical Cirrus. J. Atm. Sci., 44, 729-747.

Platt, C. M. R., et al., 2002: LIRAD Observations of Tropical Cirrus Clouds in MCTEX. Part I: Optical Properties and Detection of Small Particles in Cold Cirrus. J. Atm. Sci., 59, 3145-3162.

Ramanathan, V., R. D. Cess, E. F. Harrison, P. Minnis, B. R. Barkstrom, E. Armad, and D. Hartmann, 1989: Cloud radiative forcing and climate: Results from the Earth Radiation Budget Experiment, Science, 243, 57-63. 
Rossow, W. B., and R. A. Schiffer, 1991: ISSCP cloud data products. Bull. Amer. Meteor. Soc., 72, $2-20$.

Russell, P B; L. Pfister, and H. B. Selkirk, 1993: The Tropical Experiment of the StratosphereTroposphere Exchange Project (STEP): Science objectives, operations, and summary findings. J. Geophys. Res., 98, D5, 8563-8589.

Ryan, B. F., G. M. Barnes, and E. J. Zipser, 1992: A wide rainband in a developing tropical cyclone. Mon. Wea. Rev., 120, 431-447.

Selkirk, H. B., 1993: The tropopause cold trap in the Australian monsoon during STEP/AMEX 1987. J. Geophys. Res., 98, D5, 8591-8610.

Stokes, G. M., and S. E. Schwartz, 1994: The Atmospheric Radiation Measurement (ARM) Program: Programmatic background and design of the cloud and radiation testbed. Bull. Amer. Met. Soc., 75, 1201-1221.

Toracinta, E. R., D. J. Cecil, E. J. Zipser, and S. W. Nesbitt, 2002: Radar, passive microwave, and lightning characteristics of precipitating systems in the tropics. Mon. Wea. Rev., 130, 802-824.

Turner, D., W. F. Feltz, and R. A. Ferrare, 2000: Continuous water vapor profiles from operational ground-based active and passive remote sensors. Bull. Amer. Met. Soc., 81, 1301-1317.

Webster, P. J., and R. A. Houze, 1991: The Equatorial Mesoscale Experiment (EMEX): An Overview. Bull. Amer. Met. Soc., 72, 1481-1506.

Webster, P. J., E. F. Bradley, C. W. Fairall, J. S. Godfrey, P. Hacker, R. A. Houze, R. Lukas, Y. Serra, J. M. Hummon, T. D. M. Lawrence, C. A. Russell, M. N. Ryan, K. Sahami, and P. Zuidema, 2002: The JASMINE Pilot Study. Bull. Amer. Meteor. Soc., 83, 1603-1630.

Wheeler, M., G. N. Kiladis, and P. J. Webster, 2000: Large-scale dynamical fields associated with convectively coupled equatorial waves. J. Atmos. Sci., 57, 613-640.

Zhang, M. H., J. L. Lin, R. T. Cederwall, J. J. Yio, and S. C. Xie, 2001: Objective analysis of ARM IOP data: Method and sensitivity. Mon. Wea. Rev., 129, 295-311. 


\section{Appendix A}

\section{Proteus Instruments}




\section{Appendix A}

\section{Proteus Instruments}

Broadband Hemispheric Radiometers

Several Kipp and Zonen CM-22 pyranometers and CG-4 pyrgeometers modified by Sandia look both to nadir and zenith.

Cloud, Aerosol, and Precipitation Spectrometer (CAPS)

The Cloud, Aerosol, and Precipitation Spectrometer (CAPS) is a relatively new airborne particle spectrometer developed by Droplet Measurement Technologies, Boulder, Colorado, that measures particles from 0.35 to $1550 \mu \mathrm{m}$ in diameter and liquid water content from 0.01 to $3 \mathrm{gm}^{-3}$. Thus it has the same measurement capabilities as the combined grouping of five oft used instruments: (1) the PMS forward scattering spectrometer probe, model 100 (FSSP-100), (2) the PMS FSSP-300, (3) the two-dimensional optical imaging probe (2D-OAP), (4) the hot wire probe, and (5) the multi-angle aerosol spectrometer probe (MASP). The first three of these measured size and concentration of atmospheric aerosol and cloud particles larger than $0.3 \mu \mathrm{m}$, the next measured liquid water content, and the latter aerosol size and particle composition in the upper troposphere.

The CAPS consists of five sensors: the cloud and aerosol spectrometer (CAS: $0.35-50 \mu \mathrm{m}$ ), the cloud imaging probe (CIP: $25-1550 \mu \mathrm{m}$ ), the liquid water content detector (LWCD: $0.01-3 \mathrm{gm}^{-3}$ ), and air speed sensor, and a temperature probe.

Cloud Detection Lidar (CDL)

The Cloud Detection LIDAR, or CDL, was developed by Lawrence Livermore National Laboratory (LLNL) for the ARM-UAV program based on technology from the Clementine moon mapping mission for the profiling of aerosols, profiling of optically thin clouds, and determining cloud top or base height of optically thick clouds. It features a fully eye safe $58 \mu \mathrm{J} /$ pulse $5 \mathrm{kHz}$ ND:YLF laser with a divergence of $53 \mu \mathrm{rad}$, a wavelength of $1.053 \mu \mathrm{m}$, and a pulse width of $20 \mathrm{~ns}$. The receiver telescope has a $20 \mathrm{~cm}$ aperture and $75 \mu \mathrm{rad}$ field of view. The detector is a single-photon counting Geiger mode avalanche photodiode and is attached to multi-channel scalar set for $100 \mathrm{~m}$ binning. The entire system is designed to be rotated in flight for either nadir or zenith viewing, but is constrained to viewing either straight to the nadir or at a $3^{\circ}$ lateral offset from nadir. The CDL is contained inside the payload pod and senses through a heated window coated for maximum transmission at the laser wavelength. No special calibrations have been applied to the CDL for this campaign. 


\section{Cloud Integrating Nephelometer (CIN)}

The Cloud Integrating Nephelometer (CIN) contains four photomultiplier modules that measure $635 \mathrm{~nm}$ laser light scattered by cloud particles. One module measures forward scattered light (F), nominally between $10^{\circ}$ and $90^{\circ}$; and a second module measures backscattered light (B), nominally between $90^{\circ}$ and $175^{\circ}$. The third module measures forward scattered light $[\cos (\mathrm{F})]$ weighted by the cosine of the scattering angle, and the fourth module measures backscattered light $[\cos (\mathrm{B})]$ weighted by the cosine of the scattering angle. Experience with this instrument in other flight experiments indicates that it is not sensitive to cirrus with an optical depth less than $1 \mathrm{~km}^{-1}$ — relatively thick for experiment 2 below.

\section{Compact Millimeter Wave Radar (CMR)}

The Compact Millimeter Wave Radar (CMR) measures Doppler velocity and radar reflectivity profiles with a range resolution of $15 \mathrm{~m}$ (1000 range gates) and a sensitivity of $-42 \mathrm{dBZ}$ at $1 \mathrm{~km}$. It uses a $1 \mathrm{~W}$ continuous-wave (CW) solid-state amplifier. The 200 complex coefficients in the matched filter are programmable, allowing the radar to operate with varying chirp waveforms (different pulse lengths and bandwidths) to best match the observed scene and sensitivity requirements. The processor will perform pulse-pair averaging in real-time. This reduces the output data rate and provides Doppler velocity and reflectivity profiles via serial output in real-time for health and status verification during flight as well as permitting the storage of each profile to an internal solid-state disk for the dataset of record.

\section{Diffuse Field Camera (DFC)}

The Diffuse Field Camera (DFC) is a pair of nadir mounted moderate resolution calibrated digital cameras and associated hemispheric field-of-view lenses, one with a 620-670 nm pass band filter and the other with a 1580-1640 nm pass band filter.

In Situ State Parameters

The Proteus payload will measure in situ total pressure, static pressure, static temperature, total temperature, dew point, and frost point using a BF Goodrich Model 2014M Micro Air Data Transducer with Model 0101F Total Air Temperature Probe, General Eastern Model 1011B Dew Point Hygrometer, and a Buck Research CR-2 Cryogenic Hygrometer. The dew point and frost point temperatures will be compared to verify instrument accuracy in their sensing region overlap.

Nevzorov Probe

The Nevzorov liquid water content (LWC) and total water content (TWC) probe is described in Korolev (1998). It is a constant-temperature, hot-wire probe designed for aircraft measurements of the ice and liquid water content of clouds. 
Scanning High-Resolution Interferometer Sounder (S-HIS)

The Scanning High-Resolution Interferometer Sounder (S-HIS) is a scanning interferometer that measures emitted thermal radiation at high spectral resolution $\left(0.5 \mathrm{~cm}^{-1}\right)$ between 3.3 and $18.0 \mu \mathrm{m}$. It is an advanced version of the HIS ER-2 instrument (Smith et al. 1987, 1989;

Revercomb et al. 1988) developed between 1996 and 1998 with the combined support of the US DOE, NASA, and the MPOESS Integrated Program Office at the Space Science and Engineering Center (SSEC) at the University of Wisconsin. It has flown in several field campaigns and has proven to be dependable and effective. The measured emitted radiance is used to obtain temperature and water vapor profiles of the Earth's atmosphere. Also algorithms are currently being developed to retrieve remotely sensed sea surface skin temperature, land surface temperature and emissivity, cloud top temperature and emissivity, and trace gas total column amounts.

Scanning High-Resolution Interferometer Sounder (S-HIS)

The Scanning High-Resolution Interferometer Sounder (S-HIS) is a scanning interferometer that measures emitted thermal radiation at high spectral resolution $\left(0.5 \mathrm{~cm}^{-1}\right)$ between 3.3 and $18.0 \mu \mathrm{m}$. S-HIS scans cross-track over a range of 45 degrees off nadir, providing a $40 \mathrm{~km}$ swath from an altitude of $20 \mathrm{~km}$. The field of view of the instrument is $100 \mathrm{mrad}$ for a horizontal resolution of $2 \mathrm{~km}$ at a distance of $20 \mathrm{~km}$ from the instrument. The scanning mirror can also be turned toward zenith to provide a view of the column directly above the instrument. It is an advanced version of the HIS ER-2 instrument (Smith et al. 1987, 1989; Revercomb et al. 1988) developed between 1996 and 1998 with the combined support of the U.S. DOE, NASA, and the Polar-orbiting Operational Satellite System (MPOESS) Integrated Program Office at the Space Science and Engineering Center (SSEC) at the University of Wisconsin. It has flown in several field campaigns including Convection and Moisture Experiment (CAMEX III (1998), SAFARI (2000), and International H2O Project (IHOP) (2002) and has proven to be dependable and effective.

When scanning, S-HIS provides images of the scene below the aircraft at many wavelengths. These data can be used obtain temperature and water vapor profiles of the Earth's atmosphere. Techniques have already been developed to retrieve these profiles from ground based interferometer observations (Feltz et al. 1998; Turner et al. 2000). Some development will be required to extend these techniques to the airborne instrument. Also algorithms are currently being developed to retrieve remotely sensed sea surface skin temperature, land surface temperature and emissivity, cloud top temperature and emissivity, and trace gas total column amounts (McMillan et al. 2003). When the instrument views the zenith column, it can similarly be used to obtain temperature and water vapor profiles above the aircraft. If used in conjunction with a lidar, measurements of emission from cirrus can also be used to derive cloud microphysical properties (Platt et al. 1987; Comstock and Sassen 2001; Platt et al. 2002).

Further details for the S-HIS instrument and data from previous experiments can be found at http://deluge.ssec.wisc.edu/ shis/ 


\section{Solar Spectral Flux Radiometer (SSFR)}

The Solar Spectral Flux Radiometer (SSFR), a NASA Ames instrument, SSFR is used to measure solar spectral irradiance at moderate resolution to determine the radiative effect of clouds, aerosols, and gases on climate, and also to infer the physical properties of aerosols and clouds.

Spectral Radiance Package (SRP)

The Spectral Radiance Package (SRP) contains three separate miniature spectrometers, separate optical heads, and an autonomous data acquisition system. The two visible spectrometers, with spectral bands of 400-1050 nm and 710-800 nm, use a 2048 element cooled CCD linear array, the infrared spectrometer, with a spectral band of 1300-1500 nm, uses a cooled 512 element InGaS linear array. The field-of-view will be limited to one degree and will be nadir viewing.

Video Ice Particle Sampler (VIPS)

The Video Ice Particle Sampler (VIPS) uses a standard technology video camera to capture images of ice cloud crystals that have been captured on a continuously moving oiled tape. The video camera images an area approximately $3 \mathrm{~mm}$ by $3 \mathrm{~mm}$. This area differs from the size of the VIPS aperture, with dimensions $7 \mathrm{~mm}$ wide by $4 \mathrm{~mm}$ high. The VIPS sampling volume is given by the product of imaged area and the distance the aircraft flies during the time the imaging surface moves a distance equal to the imaged width. At an aircraft true airspeed of $100 \mathrm{~m} / \mathrm{sec}$, the sample volume is about $3 \mathrm{l} / \mathrm{sec}$ in the VIPS' current configuration. The collection efficiency of the VIPS is close to unity for particles above $10 \mu \mathrm{m}$ in size and hence a collection efficiency of unity is assumed. 
Appendix B

\section{ARA Grob G520T Egrett (VH-ARA)}




\section{Appendix B}

\section{ARA Grob G520T Egrett (VH-ARA)}

The Egrett series of aircraft has originally been developed by Grob Flugzeugbau GmbH \& Co KG (Germany) and E-Systems Inc. (USA) as a low-cost (in military terms) high altitude reconnaissance platform for the German and US Air Forces. Egrett is an acronym which combines " $E$ ” from E-Systems, " $g r$ " from Grob Flugzeugbau and "ett" from the aircraft's engine manufacturer Garrett Inc. A total of five aeroplanes were built, the single-seater Proof-of-Concept aircraft, three production single seaters, and one two-seater trainer. After an evaluation period, the two Air Forces decided that the aircraft did not fit their requirements. Since then, some of the single seaters have been successfully used as ad-hoc high-altitude research platforms, but none of them are operational today.

The Egrett is capable of carrying about $500 \mathrm{~kg}$ of scientific load to an altitude of $49,000 \mathrm{ft}(15 \mathrm{~km})$ and stay there for up to $6 \mathrm{~h}$, depending on the mission profile. Normal cruising speed (indicated air speed, IAS) at altitude is $130-150 \mathrm{kts}(65-75 \mathrm{~m} / \mathrm{s})$ with a true air speed (TAS) of about Mach $0.45(100-110 \mathrm{~m} / \mathrm{s})$. Its maximum range at altitude is about $1500 \mathrm{NM}(2800 \mathrm{~km})$. The aircraft can operate from most sealed runways. No special airport infrastructure is required. It is powered by a single Garrett turboprop engine (TPE331-14) and is certified as a normal aircraft under Australian regulations for flight under all-weather conditions (IFR/icing). The normal crew consists of a pilot occupying the front seat and a systems operator/scientist occupying the rear seat.

For an aircraft with a nose-mounted propeller the only real option for the fitting of sensors and air intakes at locations unaffected by both the propeller slipstream and the exhaust from the engine is under the wings. Wing pylons and masts carrying turbulence and other probes are available.

As the Egrett was originally designed as a reconnaissance aircraft, its modular fuselage structure offers ample and simple options for a large number of downward- or sideward-looking apertures in the fuselage. The whole lower section of the forward fuselage, the so-called $U$-Bay, is non-structural and modifications to this part are extremely simple.

Due to the modular design of the Egrett's fuselage, there is ample space available for mounting user instrumentation within the fuselage. Most of this space is within the unpressurised section of the fuselage. The ARA data system is installed within the pressurised cockpit area. The Egrett has 100A at $28 \mathrm{~V}$ and about $7.5 \mathrm{kVA}$ of $115 \mathrm{VAC}$ at $400 \mathrm{~Hz}$ available for powering the scientific instrumentation. 


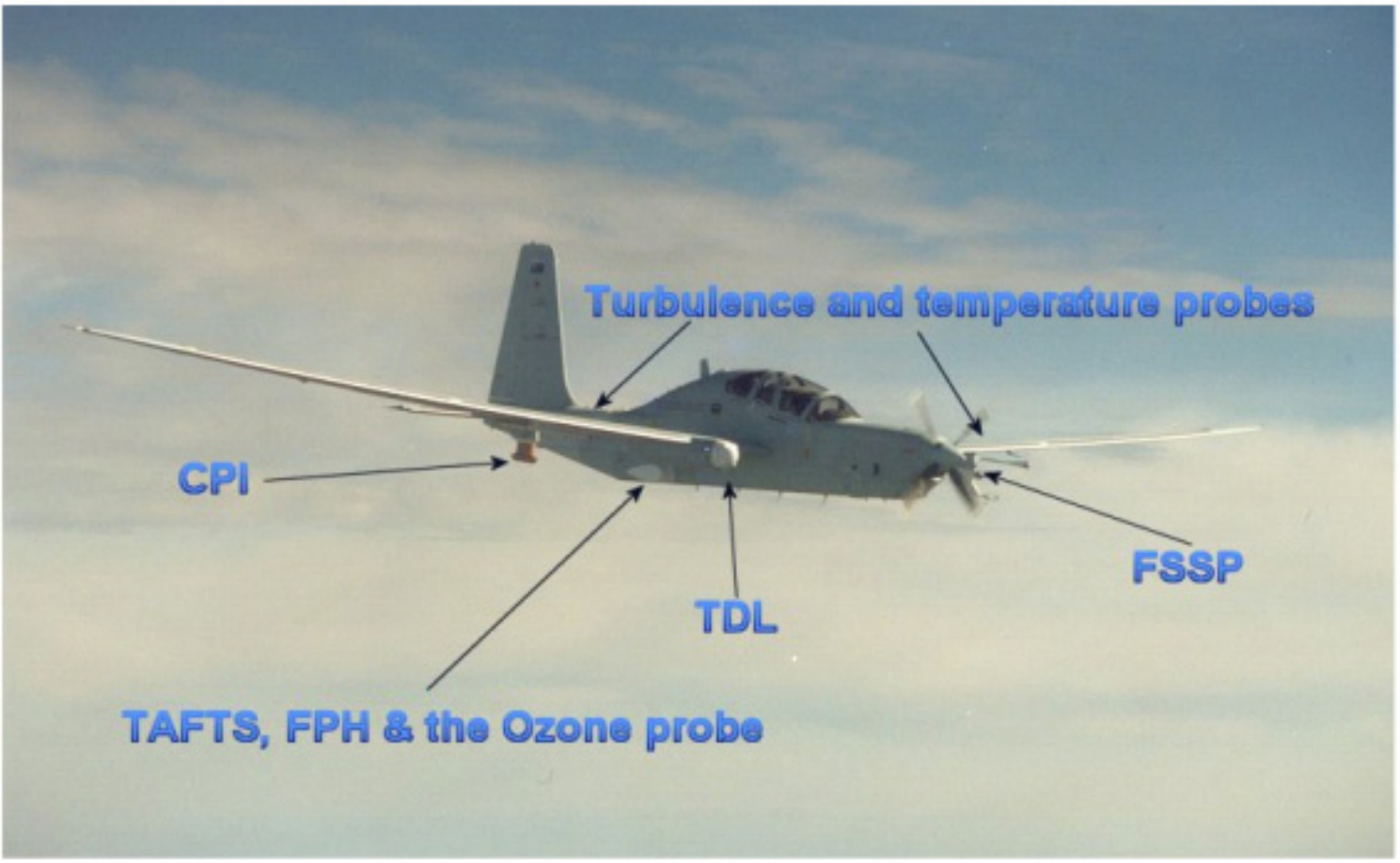

The ARA Grob G520T Egrett high-altitude research aircraft and its sensors during EMERALD-2.

For the Darwin 2006 Experiment, the Egrett will be carrying a suite of in situ microphysical measurements and an upward and downward looking lidar system for lidar backscatter measurements currently under development by Jim Whiteway in Canada.

The combination of the Proteus and Egrett will allow simultaneous sampling of the upper and lower parts of the cirrus anvils as well as remote measurements.

The EMERALD-2 payload was approximately $450 \mathrm{~kg}$ with $100 \mathrm{~kg}$ for the Fourier transform spectrometer (TATFS) instrument in the U-Bay. This instrument will not be used during the Darwin 2006 measurements.

Of the instruments in the list below, the Lidar, the dropsondes, the SP-2 and the AeroLaser have not been flown on the Egrett yet. A dropsonde system suitable for the Egrett would be the Vaisala Lite-AVAPS with minor modifications. No funding has been applied for this instrument so far.

It is possible to add up- and downward-looking short- and longwave hemispheric radiometers to the package. ARA owns such a set, but discussions are required with ARM about the mounting location and funding has to be found. 


\section{Grob G520T Egrett - Wing pods and hardpoints}

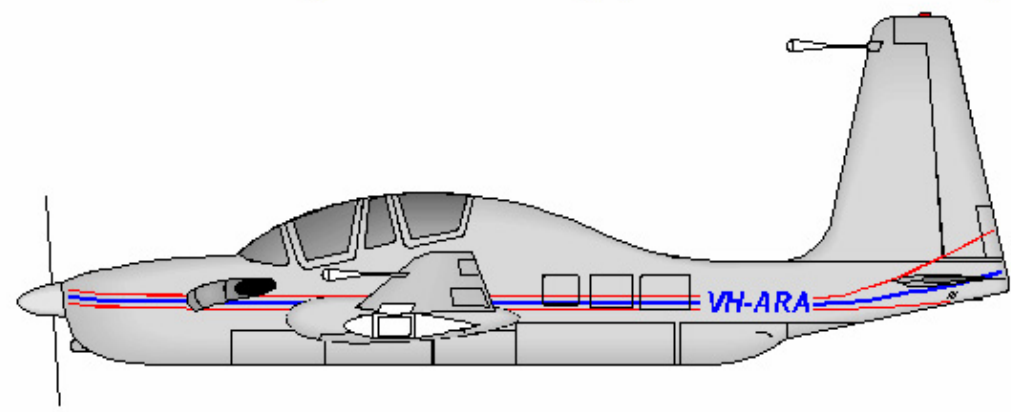

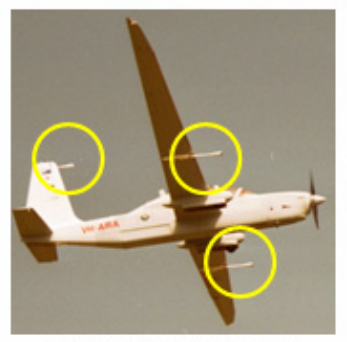

Wing/tail masts with turbulence probes
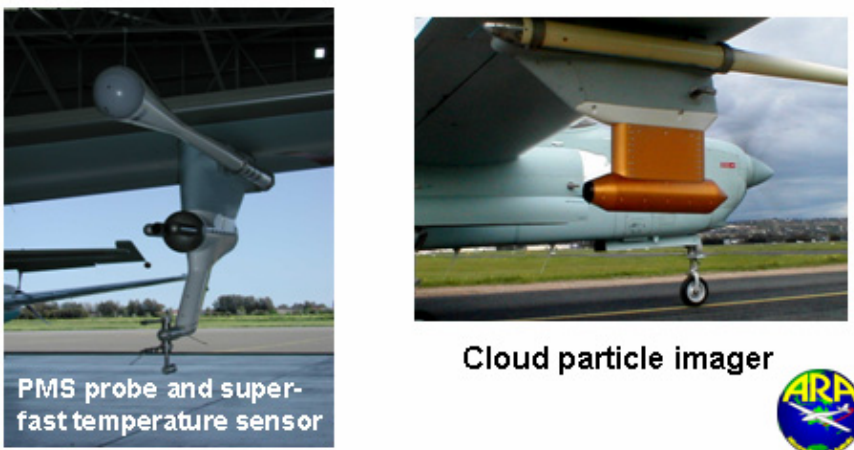

Cloud particle imager

\section{Grob G520T Egrett - Instrumentation bays}

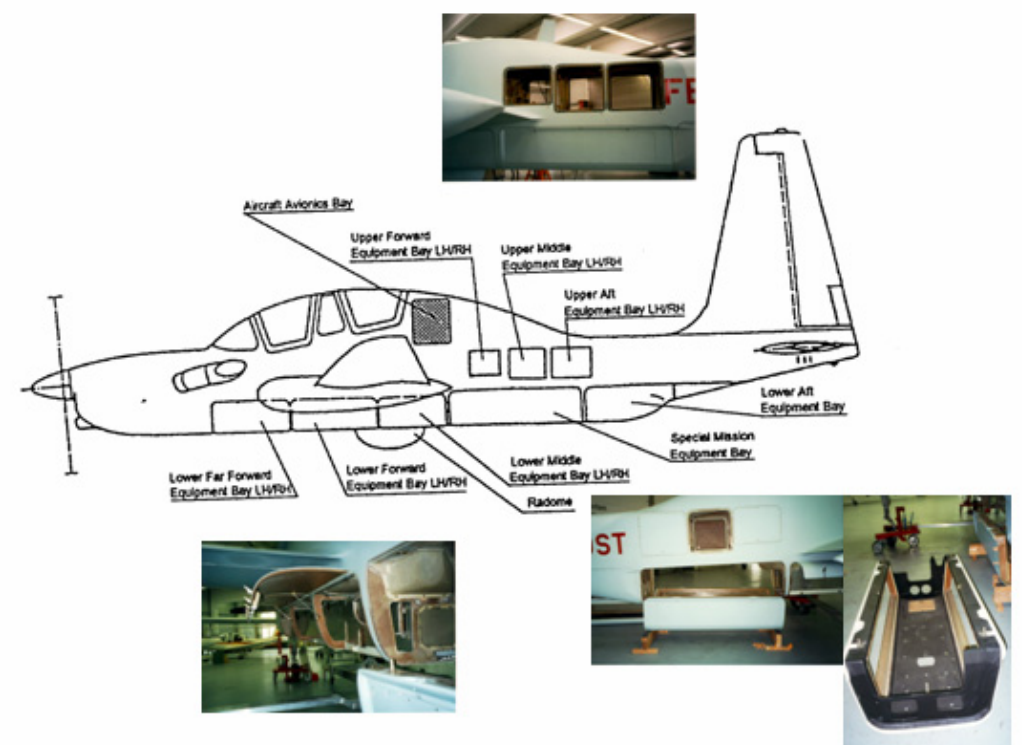




\begin{tabular}{|c|c|c|c|c|}
\hline Instrument & $\begin{array}{c}\text { Measurements } \\
\end{array}$ & Supplier & Institution & Comments \\
\hline Lidar & Cloud structure and water vapour $14-18 \mathrm{~km}$ & York & York & $\begin{array}{l}\text { under development by Jim } \\
\text { Whiteway } \\
\text { mounted in fuselage } \\
\text { details required } \\
\text { can probably not be flown } \\
\text { together with PS-2 }\end{array}$ \\
\hline $\begin{array}{l}\text { Single Particle Soot } \\
\text { Photometer } \\
\text { (PS-2) }\end{array}$ & $\begin{array}{l}\text { Single particle component spectrometer \& aerosol } \\
\text { size distribution }[0.2<\mathrm{Dp}<1.0 \mu \mathrm{m}] \text {. } \\
\text { Measures single particle incandescence } \\
\text { temperature, highly specific to black carbon but } \\
\text { also identifies other light absorbing particles. } \\
\text { Measures } \\
\text { black carbon mass [ }>0.02 \mathrm{pg} \mathrm{m}-3] \\
\text { light absorbing aerosol fraction, identifies metal } \\
\text { components. }\end{array}$ & $\begin{array}{l}\text { DMT, } \\
\text { Boulder, } \\
\text { Colorado, } \\
\text { USA. }\end{array}$ & UMIST & $\begin{array}{l}\text { Hired from DMT. } \\
\text { Instrument plus computer to be } \\
\text { mounted in U-bay. } \\
\text { Occupies at least } 50 \% \text { of U-bay, } \\
\text { more if pressurised? } \\
\text { Size of pump unknown yet. }\end{array}$ \\
\hline $\begin{array}{l}\text { Cloud, Aerosol \& } \\
\text { Precipitation } \\
\text { Spectrometer } \\
\text { (CAPS) } \\
\text { Multiple instruments } \\
\text { in one canister. }\end{array}$ & $\begin{array}{l}\text { 1. } \\
\text { 2. "Drosol Size }\left[0.3<\mathrm{D}_{\mathrm{p}}<1 \mu \mathrm{m}\right] \\
\text { 3. Precipitation } / \mathrm{Ice} 2-\mathrm{D} \text { shadow images } \\
\quad\left[25<\mathrm{D}_{\mathrm{p}}<1,550 \mu \mathrm{m}\right] \\
\text { 4. Hot-wire liquid water/total water content } \\
\quad \text { sensor (LWC-100) range } 0.01-3.0 \mathrm{~g} \\
\quad \mathrm{~m}^{-3} \text { at } 100 \mathrm{~Hz} \text {. } \\
\text { 5. Pitot tube for sample air. }\end{array}$ & $\begin{array}{l}\text { DMT, } \\
\text { Boulder, } \\
\text { Colorado, } \\
\text { USA. }\end{array}$ & UMIST & $\begin{array}{l}\text { To be supplied by Prof. A. } \\
\text { Heymsfield, NCAR, collaborator } \\
\text { on proposal. } \\
\text { On existing PMS l/h wing pylon }\end{array}$ \\
\hline $\begin{array}{l}\text { Cloud Particle } \\
\text { Imager } \\
(\mathrm{CPI}-230)\end{array}$ & $\begin{array}{l}\text { Ice crystal/particle size distribution } \\
{[10 / 40<\mathrm{Dp}<2,300 \mu \mathrm{m}] \text {, resolution } 2.4 \mu \mathrm{m} \text {. }} \\
\text { Real-time CCD particle images for ice habit } \\
\text { identification }(40 \mathrm{~Hz})\end{array}$ & $\begin{array}{l}\text { Stratton Park } \\
\text { Engineering } \\
\text { Co., Boulder, } \\
\text { Colorado, } \\
\text { USA. }\end{array}$ & UMIST & $\begin{array}{l}\text { JIF UFAM Instrument supplied } \\
\text { by UMIST. } \\
\text { Sample volume must be } \\
\text { corrected by CAPS data. } \\
\text { On existing PMS l/h wing pylon. }\end{array}$ \\
\hline
\end{tabular}


Table B-1. (contd)

\begin{tabular}{|c|c|c|c|c|}
\hline \multicolumn{5}{|c|}{ Table B-1. (contd) } \\
\hline Instrument & Measurements & Supplier & Institution & Comments \\
\hline $\begin{array}{l}\text { Cloud Droplet Probe } \\
\text { (CDP) }\end{array}$ & $\begin{array}{l}\text { Droplet/Particle size distribution }[2<\mathrm{Dp}<75 \mu \mathrm{m}] \text {. } \\
\text { Particle inter-arrival time. } \\
\text { No inlet, to assess particle break-up on inlet issues. }\end{array}$ & $\begin{array}{l}\text { DMT, } \\
\text { Boulder, } \\
\text { Colorado, } \\
\text { USA. }\end{array}$ & UMIST & $\begin{array}{l}\text { Miniature cloud spectrometer } \\
\text { (backup instrument + NERC } \\
\text { CAMP testing component). } \\
\text { On existing PMS l/h wing pylon }\end{array}$ \\
\hline AeroLaser 5200 [CO] & resolution $<2.0 \mathrm{ppb}$, response time $10 \mathrm{~Hz}$. & $\begin{array}{l}\text { Aero Laser } \\
\text { GmbH, } \\
\text { Germany }\end{array}$ & UMIST & $\begin{array}{l}\text { U-Bay or fuselage } \\
\text { more details required } \\
\text { DLR or MetAir? }\end{array}$ \\
\hline $\begin{array}{l}\text { TECO-43C Ozone } \\
\text { [O3] }\end{array}$ & Resolution $2 \mathrm{ppb}$, response time $10 \mathrm{~s}$ & TECO & York/DLR & in rear fuselage \\
\hline $\begin{array}{l}\text { Laser Hygrometer } \\
\text { (TDL) }\end{array}$ & Water Vapour [H2O] & $\begin{array}{l}\text { Buck Research } \\
\text { USA }\end{array}$ & York & In landing gear pod \\
\hline $\begin{array}{l}\text { Buck Research CR-2 } \\
\text { Frost Point } \\
\text { Hygrometer }\end{array}$ & Temperature, Dew Point \& Frost Point & $\begin{array}{l}\text { Buck Research } \\
\text { USA }\end{array}$ & York/DLR & U-Bay or fuselage \\
\hline Nevzorov Probe & Total water/ice content & $?$ & UMIST & TBD \\
\hline $\begin{array}{l}\text { Vaisala Lite-AVAPS } \\
\text { Drop sonde system }\end{array}$ & temperature and water vapour $14-0 \mathrm{~km}$ & Vaisala & $?$ & $\begin{array}{l}\text { tail section of fuselage (TBD) } \\
\text { funding unclear }\end{array}$ \\
\hline BAT-Probe & wind, turbulence (50Hz), pitot-static & ARA & ARA & mast on $\mathrm{l} / \mathrm{h}$ wing pylon \\
\hline $\begin{array}{l}\text { Rosemount 5-hole } \\
\text { probe }\end{array}$ & wind, turbulence (20Hz), pitot-static (de-iced) & ARA & ARA & mast on $\mathrm{r} / \mathrm{h}$ wing pylon \\
\hline FUST sensor & fast temperature & ARA & ARA & on BAT-Probe \\
\hline $\begin{array}{l}\text { Rosemount PT500 \& } \\
\text { PT50 }\end{array}$ & temperature (de-iced) & Rosemount & DLR/ARA & r/h wing pylon \\
\hline Eppley radiometers & $\begin{array}{l}\text { solar and terrestrial radiation } \\
\text { up- and down-welling }\end{array}$ & Eppley & ARA & TBD with ARM \\
\hline Novatel 12-ch GPS & position, altitude, ground speed & Novatel & ARA & in fuselage \\
\hline $\begin{array}{l}\text { Trimble TANS } \\
\text { Vector }\end{array}$ & attitude (pitch, roll, heading), $10 \mathrm{~Hz}$ & Trimble & ARA & $\begin{array}{l}\text { in fuselage, } 2 \text { independent } \\
\text { systems }\end{array}$ \\
\hline 3D accelerometers & 3D-accelerations, 3D-attitude rates & Crossbow & ARA & 3 packages (wings, fuselage) \\
\hline
\end{tabular}




\section{ARA Becch 200T Super King Air (VH-LAB)}

Until recently, ARA owned the former National Center for Atmospheric Research (NCAR) King Air (formerly N312D). Due to lack of use in the Australian research environment, ARA sold the aircraft to an operator in NSW/Australia. However, arrangements are in place that ARA can lease the aircraft back for the Darwin 2006 study (and other studies, if required).

The Super King Air is an all-metal, low-wing, pressurized aircraft. It is powered by two Pratt and Whitney PT6-42 turboprop engines. It is approved for flight in known icing conditions. The minimum flight crew is one pilot; the copilot's seat can be made available for a scientific observer should singlepilot operation be permissible for a particular mission.

The aircraft has a cabin of oval cross section (about $5.0 \mathrm{~m} \times 1.30 \mathrm{~m}$ x $1.24 \mathrm{~m}$ ) with a door on the left-hand side $(0.66 \mathrm{~m} \times 1.27 \mathrm{~m})$. The aircraft is capable of lifting approximately 1,200 $\mathrm{kg}$ of useful load, has a maximum endurance of about $8 \mathrm{~h}$, a maximum range of 3,000 km, depending on the flight level and mission type, and can operate up to 35,000 ft. The aircraft has full de-icing and anti-icing systems installed. Electrical power available for research purposes is approximately $325 \mathrm{~A} / 28 \mathrm{~V}$.

The aircraft is fitted with a (heated) radome differential pressure gust probe. Ten fuselage apertures $(12 \mathrm{~cm} \times 17 \mathrm{~cm})$ are located on top of the aircraft. These locations can accommodate mounting of equipment such as air sample inlets and exhausts, scoops, cloud water collectors, and radiation flux sensors. The equipment can be attached to the outside or inside, or it can extend through the aperture plate and span between two plates if required.

Fuselage hardpoints are located on the bottom and on the top centerline of the fuselage. They consist of a rectangular bolt pattern with a through-bulkhead electrical connector in the centre. These hardpoints may be used to attach small fairings or pods to the exterior of the aircraft with only an electrical connection to the interior.

A downward viewing port is available through the aft right cabin floor for tasks such as down-looking photography, radiometry, and dispensing chaff and dropsondes. The view-port consists of an oval-shaped hole, $24 \mathrm{~cm}$ by $30 \mathrm{~cm}$ that is situated in the cabin floor between the seat rails. Another hole that extends through the aircraft skin, which is $47 \mathrm{~cm}$ in diameter and circular in shape, is located directly below and slightly inboard of the oval-shaped cabin floor opening. This opening accepts a 47-cm diameter plate, or plates can be machined to mount specialized equipment with bolt patterns to adapt this plate. As this plate acts as a pressure interface, it must be in place at all times to maintain cabin pressurization.

Two under-wing hardpoints are located on the outboard wing panels on each side, well outside the prop wash area. The mounts can be used primarily for pods or flush-mounted fairings to carry down-, rear- or forward-looking devices, or similar equipment. An instrument pod is attached to each wing tip to carry permanently mounted sensors, principally particle spectrometer probes, manufactured by Particle Measuring Systems, Inc. (PMS). The PMS probe case structure can be used to carry other equipment when the PMS measurement capability is not required. 
A large under-belly pod is also available.

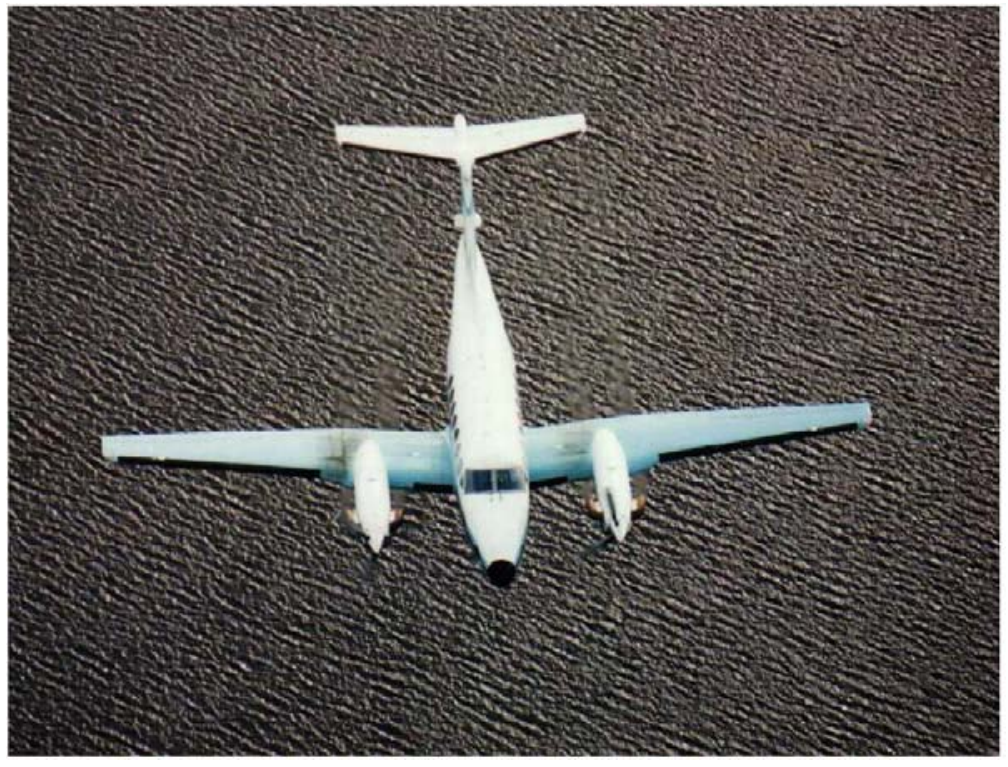

During Darwin 2006, it is envisaged that the aircraft will fly at altitudes up to $5000 \mathrm{~m}$. In terms of airspeed, it is capable of flying stacked legs with the Egrett and Proteus. Instrumentation will include an elastic backscatter polarization lidar with an output of $30 \mathrm{~mJ}$ per pulse at $532 \mathrm{~nm}$ and a PRF of $20 \mathrm{~Hz}$. The detector uses a 10-cm telescope detecting two components of polarization relative to output using photon counting. The vertical resolution is $30 \mathrm{~m}$ and the temporal sampling of averaging over $2.5 \mathrm{~s}$, corresponds to horizontal distance of $250 \mathrm{~m}$ on the King Air. A 94-GHz cloud radar for sampling the optically thick cirrus will also be used. The aircraft will also be instrumented with in situ measurements for atmospheric state parameters, such as temperature, humidity, and wind. 


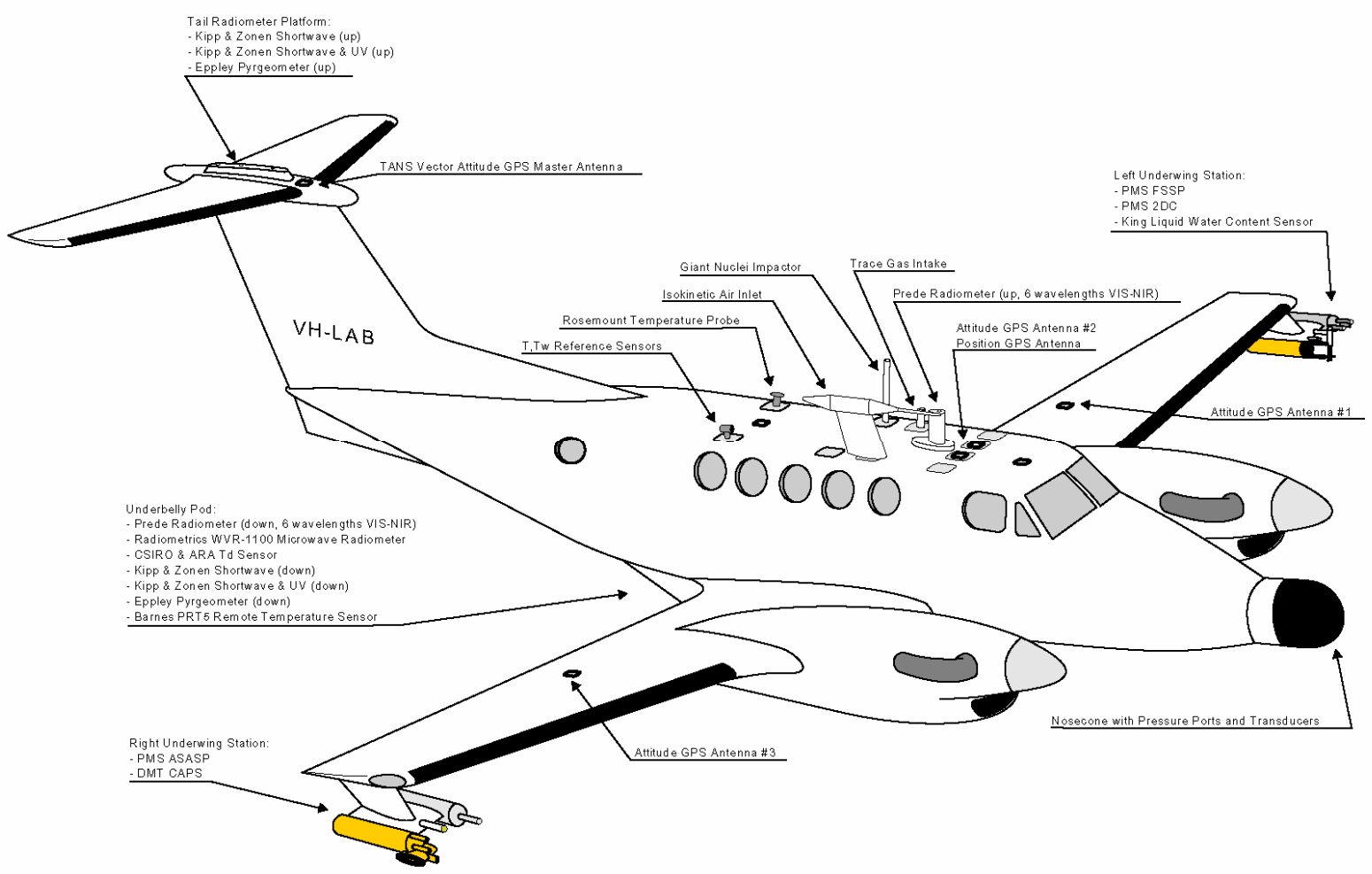

The ARA King Air During the ACE-Q Asia and APEX-E2 Experiment.

\section{ARA ECO-Dimona (VH-EOS)}

The Dimona HK36 TTC-ECO is a two seater single engine SERA ("Small Environmental Research Aircraft”). It carries two underwing pods for instrumentation (suitable for 19"/6HU instruments), and can also carry instrumentation in the cockpit. Maximum take-off weight is $930 \mathrm{~kg}$. The crew normally consists of a pilot/scientist and a second person (observer, scientist, operator), but the instrumentation is set up to be operated by a pilot/scientists alone.

Maximum payload is $50 \mathrm{~kg}$ in each pod, $30 \mathrm{~kg}$ in the cockpit behind the seats and $110 \mathrm{~kg}$ on the $\mathrm{r} / \mathrm{h}$ seat (either second person or instrumentation). Typical endurance is approximately $5 \mathrm{~h}$ at a cruising speed of $95 \mathrm{kts}$, also depending on the flight profile and power setting. Operations 1 ceiling is approximately $20,000 \mathrm{ft}$, with a requirement to carry breathing oxygen for operations above $10,000 \mathrm{ft}$.

Electrical power available is primary 28VDC/1000W. Other voltages (12VDC/240VAC) can be accommodated.

In Australia, in general, operations over water with single-engine aircraft such as the Dimona are unrestricted, subject to carrying or wearing lifejackets. Operations at low altitude as required for flux measurements require special procedures and it might be difficult to be gain approval for such flights beyond a few kilometers from land, except if there is a vessel in the vicinity. 
The basic instrumentation carried by the Dimona consists of fast sensors for wind, turbulence, air temperature, humidity and $\mathrm{CO}_{2}$, plus aircraft parameters (position, altitude, attitude angles, and rates, accelerations) suitable for eddy-flux measurements. Additional sensors for surface temperature, as well as up- and down-welling solar and terrestrial radiation can be added.

A Scanning Low-Frequency Microwave Radiometer (P-SLFMR) combined with an IR-imager can be fitted to the aircraft for measurements of soil moisture and Sea Surface Salinity. If required, a line scanner (1-m resolution) can be flown for Normalized Differential Vegetation Index (ndvi).

For the Darwin-2006 Experiment, it is proposed to fit the air chemistry under-wing pod of the ECODimona operated by MetAir AG in Switzerland to the ARA ECO-Dimona. Specifications of this package are given below.

Additional instrumentation can be fitted in the baggage area of the aircraft, as for instance flasks for air samples.

This aircraft will be dedicated to making detailed in situ measurements in the boundary layer. Key roles will be the mapping of near surface fluxes to sample the spatial variability of the fluxes to complement the ground/ship based observations. The aircraft will also be used to sample the boundary layer structure near the developing convection.

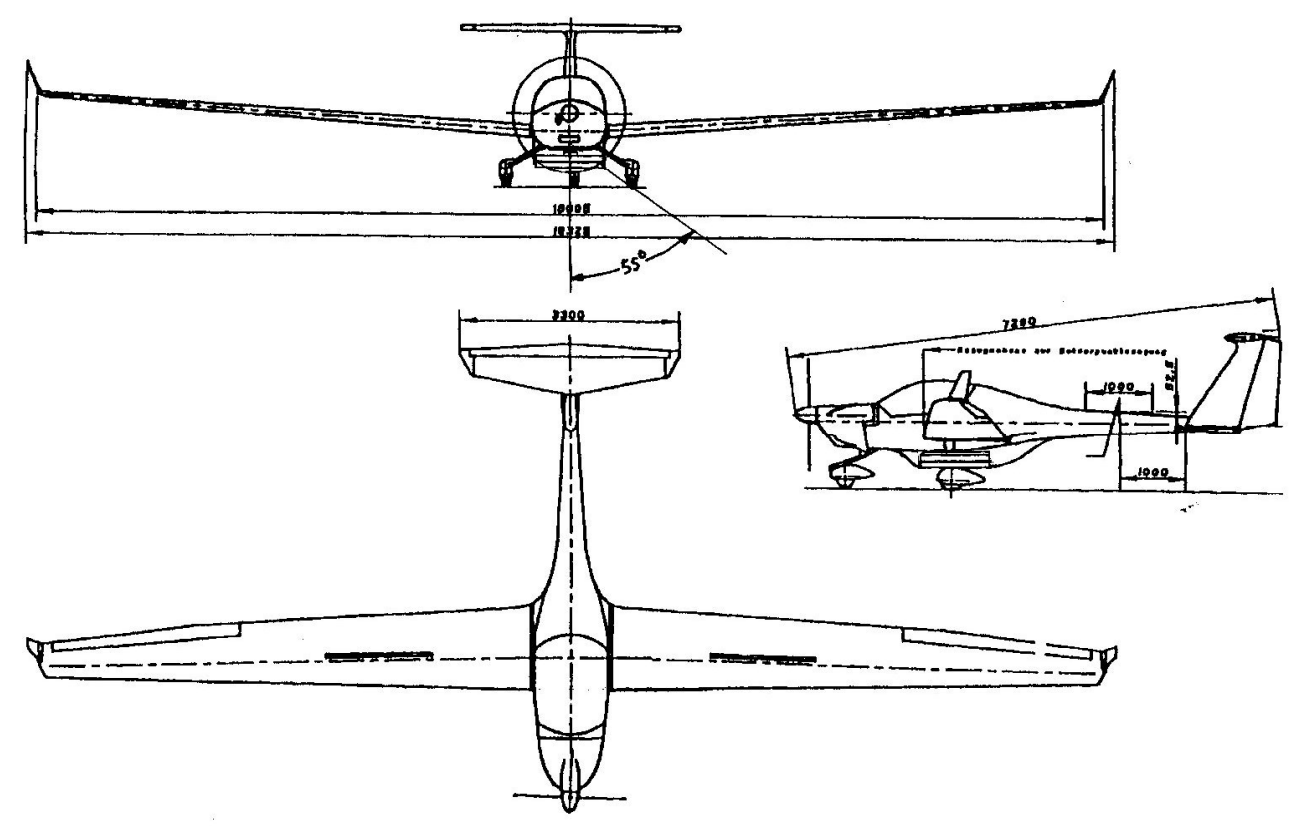




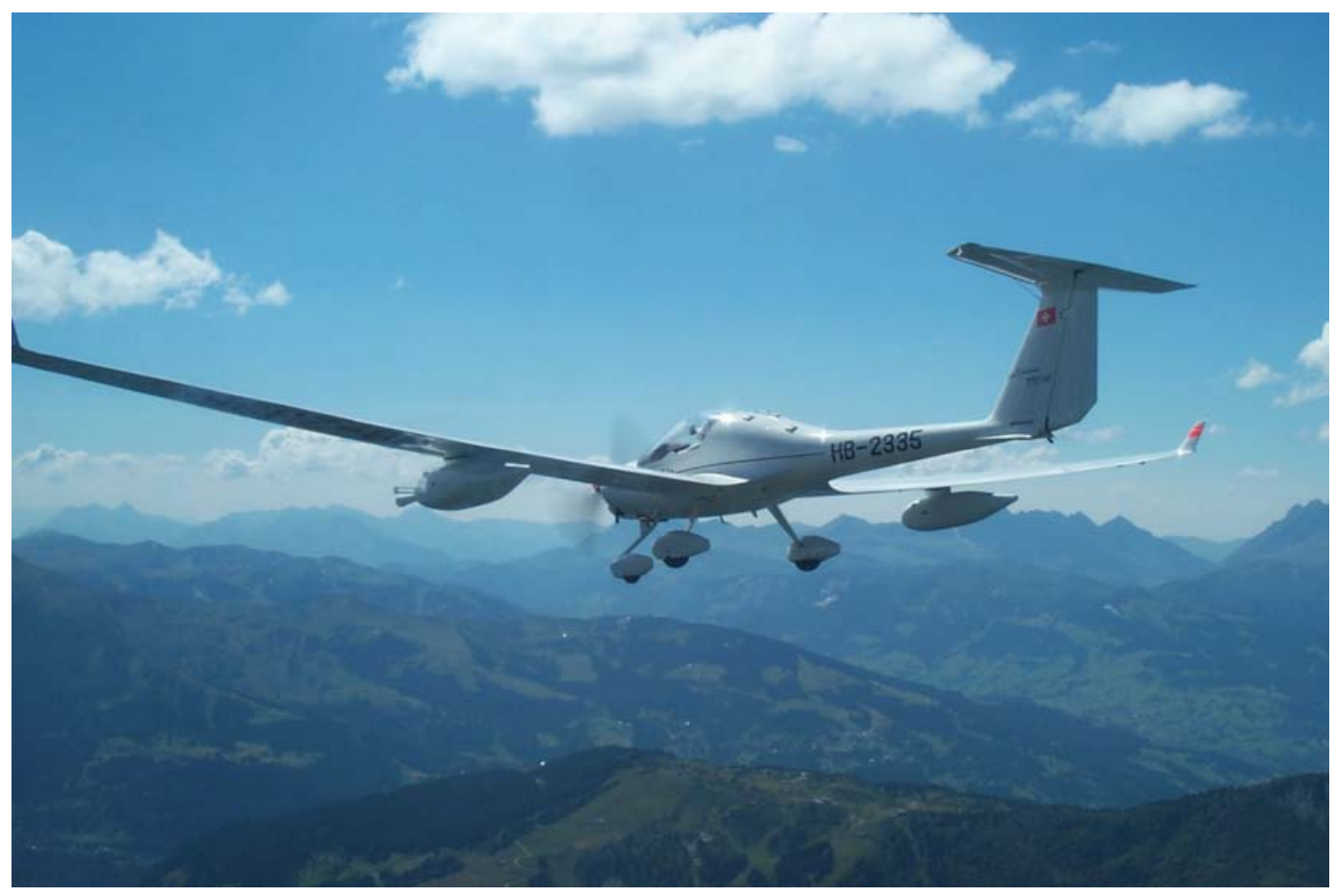

\section{MetAir Eco-Dimona}

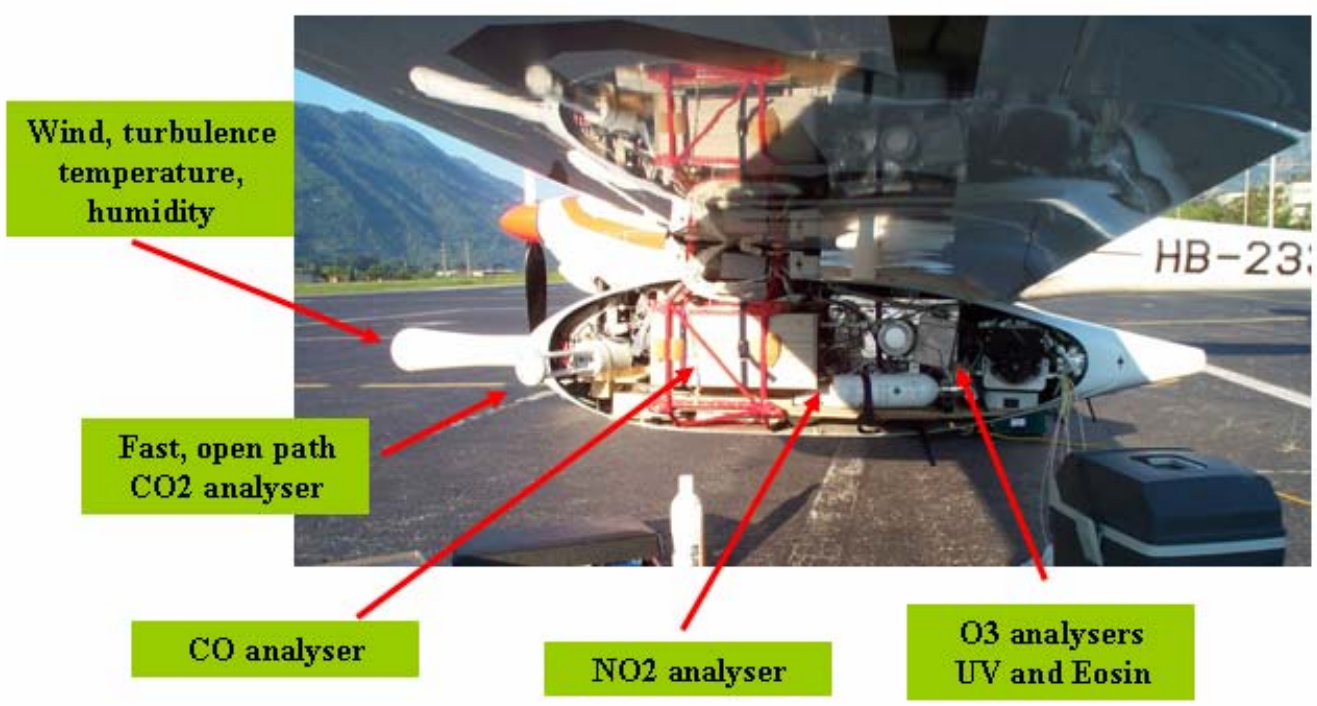


Table B.2. Instrumentation on the ECO-Dimona (some optional or under discussion).

\begin{tabular}{|c|c|c|c|c|}
\hline Instrument & Measurements & Supplier & Institution & Comments \\
\hline LiCor 7500 IR gas analyzer & $\begin{array}{l}\text { Water Vapour }\left[\mathrm{H}_{2} \mathrm{O}\right] \\
\mathrm{CO}_{2}\end{array}$ & LiCor USA & ARA & \\
\hline BAT-Probe & wind, turbulence (50Hz), pitot-static & ARA & ARA & \\
\hline FUST sensor & fast air temperature & ARA & ARA & \\
\hline PT100 in housing (2) & air temperature & ARA & ARA & \\
\hline Eppley radiometers & $\begin{array}{l}\text { solar and terrestrial radiation } \\
\text { up- and down-welling }\end{array}$ & Eppley & ARA & TBD with ARM \\
\hline Novatel 12-ch GPS & position, altitude, ground speed & Novatel & ARA & in fuselage \\
\hline Trimble TANS Vector & attitude (pitch, roll, heading), $10 \mathrm{~Hz}$ & Trimble & ARA & in fuselage, 2 independent systems \\
\hline 3D accelerometers & 3D-accelerations, 3D-attitude rates & Crossbow & ARA & 3 packages (wings, fuselage) \\
\hline MetOneParticle counter & particles 0.3 to $0.5 \mu \mathrm{m}$ & MetAir & ARA/MetAir & \\
\hline PSI UV Ozone & Ozone $\left[\mathrm{O}_{3}\right] 2 \mathrm{ppb}-1 \mathrm{ppm}$ & MetAir/PSI & ARA/MetAir & \\
\hline MetAir NOxTOy & $\mathrm{NO}_{2}, \mathrm{NO}_{\mathrm{x}}, \mathrm{NOy}, \mathrm{HNO}_{3}$, PAN, Ox & MetAir & ARA/MetAir & 6-channel Luminol detector \\
\hline LiCor 6262 & $\begin{array}{l}\text { high accuracy } \mathrm{CO}_{2}, 0.05 \mathrm{ppm} \text { accuracy }(1 \mathrm{~Hz}) \\
\mathrm{H}_{2} 0,0.01 \mathrm{~g} / \mathrm{kg} \text { accuracy }(1 \mathrm{~Hz})\end{array}$ & LiCor/MetAir & ARA/MetAir & \\
\hline AeroLaser AL-5003 & $\mathrm{CO}, 1 \mathrm{ppb}$ accuracy, $10 \mathrm{~Hz}$ & $\begin{array}{l}\text { AeroLaser/ } \\
\text { MetAir }\end{array}$ & ARA/MetAir & \\
\hline IFU/PSI & Formaldehyde (HCHO) & & ARA/MetAir & \\
\hline AeroLaser & Peroxides $\left(\mathrm{H}_{2} \mathrm{O}_{2}\right.$ and organic $)$ & AeroLaser & ARA/MetAir & \\
\hline TSI particle counter & Particles $>10 \mathrm{~nm}$ & TSI & ARA/MetAir & \\
\hline P-SLFMR/IR-Imager & Soil moisture, Sea Surface Salinity, SST & $\begin{array}{l}\text { ARA/UM/ } \\
\text { FLIR }\end{array}$ & ARA & \\
\hline
\end{tabular}




\title{
Appendix C
}

\author{
Contacts
}




\section{Appendix C}

\section{Contacts}

Peter May

Christian Jakob

Tom Keenan

John McBride

Jorg Hacker

Jim Whiteway

Stuart Young

Martin Platt

Chuck Long

T. Ackerman

Jim Mather

John Vitko

Greg McFarquhar

Rick Cederwall

Tim Tooman

MingHua Zhang

Hank Revercomb

Jay Mace

Mark Miller

Nigel Tapper p.may@bom.gov.au

c.jakob@gov.au

t.keenan@bom.gov.au

j.mcbride@bom.gov.au

jorg.hacker@flinders.edu.au

whiteway@yorku.ca

stuart.young@dar.csiro.au

mplatt@net2000.com.au

chuck.long@pnl.gov

ackerman@pnl.gov

jim.mather@pnl.gov

jvitko@sandia.gov

mcfarq@atmos.uiuc.edu

rcederwall@llnl.gov

tooman@sandia.gov

mzhang@notes.cc.sunysb.edu

hankr@ssec.wisc.edu

Mace@met.utah.edu

miller@bnl.gov

Nigel.Tapper@arts.monash.edu.au 